\title{
From Microbiome to Inflammation: The Key Drivers of Cervical Cancer
}

\author{
Zi-Wei Zhou',2, Hui-Zhi Long1,2, Yan Cheng, ${ }^{1,2}$, Hong-Yu Luo ${ }^{1,2}$, Dan-Dan Wen ${ }^{1}$ and \\ Li-Chen Gao ${ }^{1,2 *}$ \\ ${ }^{1}$ Department of Pharmacy, Cancer Institute, Phase I Clinical Trial Centre, The Affiliated Changsha Central Hospital, \\ Hengyang Medical School, University of South China, Hengyang, China, ${ }^{2}$ Hunan Provincial Key Laboratory of Tumor \\ Microenvironment Responsive Drug Research, Hengyang, China
}

Cervical cancer is the third leading cause of cancer-related death worldwide. Microbes and hosts form a mutually beneficial symbiosis relationship, and various parts of the host body are microbial habitats. Microbes can trigger inflammation in certain parts of the host body, contributing to cervical cancer development. This article reviews the relationship between cervicovaginal microbes, inflammation and cervical cancer, and discusses the effect of some key cervical microbes on cervical cancer. Finally, probiotic therapy and immunotherapy are summarized.

\section{OPEN ACCESS}

Edited by:

Traci Testerman,

University of South Carolina,

United States

Reviewed by:

Stefano Cacciatore International Centre for Genetic Engineering and Biotechnology

(ICGEB), South Africa

Tingtao Chen,

Nanchang University, China

${ }^{*}$ Correspondence:

Li-Chen Gao

89206346@qq.com

Specialty section:

This article was submitted to Microbial Immunology, a section of the journal

Frontiers in Microbiology

Received: 31 August 2021

Accepted: 21 October 2021

Published: 15 November 2021

Citation:

Zhou Z-W, Long H-Z, Cheng Y,

Luo H-Y, Wen D-D and Gao L-C

(2021) From Microbiome

to Inflammation: The Key Drivers

of Cervical Cancer.

Front. Microbiol. 12:767931. doi: 10.3389/fmicb.2021.767931
Keywords: microbiome, inflammation, cervical cancer, probiotic, immunotherapy

\section{INTRODUCTION}

Cervical cancer is one of the most significant malignancies in females, and the third leading cause of cancer-related deaths worldwide. It has been estimated that there are about 530,000 new cases and 275,000 deaths worldwide each year (Olusola et al., 2019). Cervical cancer is the most common cancer in Eastern Africa (Ferlay et al., 2019). The cervix surface comprises two kinds of epithelial cells layers: the outer squamous cells and columnar glandular cells along the inner canal. The junction of columnar cells and squamous cells is termed the squamocolumnar junction. This junction is prone to precancerous lesions and canceration. In the early stages, cervical cancer is often unnoticed due to the inconspicuous symptoms. However, many common symptoms such as vaginal bleeding, abnormal vaginal discharge, and dyspareunia occur when cervical cancer advances to the terminal stage (Reed et al., 2021). Although the development of cervical cancer could be prevented by routine screening and other treatment approaches, mortality rates do not decrease significantly. It is urgently needed to explore standard treatments for cervical cancer.

Inflammation is a kind of defense mechanism to various stimuli. Tissue damage and various contributing factors can trigger inflammation. When the host body shows inflammatory signs, it results in the following phenomenon: elevated cellular metabolism, vessel wall dilatation, the release of soluble mediators and increased blood flow (Ferrero-Miliani et al., 2007). The inflammation period is classified into an acute period and a chronic period. Immune cells migrate to the injury site

Abbreviations: CSTs, community state types; CT, Chlamydia trachomatis; HPV, human papillomavirus; BV, bacterial vaginosis; CIN, cervical intraepithelial neoplasia; AMPs, antimicrobial peptides; MBL, Mannose-binding lectin; GCDC, glycochenodeoxycholate; PID, pelvic inflammation; LSIL, low-grade squamous intraepithelial lesions; HSIL, highly squamous intraepithelial lesions; CVL, cervix vaginal lavage; STI, sexually transmitted infection; ROS, reactive oxygen species; KG, Kaempferol-7-O-b-D-glucoside; EMMPRIN, extracellular matrix metalloproteinase inducer; MMP-8, matrix metalloproteinase-8; MMP, matrix metalloproteinase; IL, interleukin; TGF- $\beta 1$, transforming growth factor- $\beta 1$; TNF- $\alpha$, tumor necrosis factor- $\alpha$; TLRs, toll-like receptors; STAT, signal transducers and activators of transcription; JAK, janus kinase; NF-кB, nuclear factor- $\kappa$-gene binding. 
to initiate inflammation by regulating soluble mediators in the acute phase. Persistent inflammation contributes to the chronic period. The salient feature of chronic inflammation could be explained by lymphocytic infiltration. Antibodies or cytokines are secreted by $\mathrm{T}$ and $\mathrm{B}$ lymphocytes, which are involved in tissue damage and inflammatory cell recruitment. Chronic inflammation can lead to atherosclerosis, diabetes, aging, autoimmune diseases, and even cancers (Gabay and Kushner, 1999; Castellon and Bogdanova, 2016; Germolec et al., 2018).

The microflora is a collection of living microbes that live in biological organs. There are various microbes on the body's surface, and the human body is a habitat of trillions of microbes (Adak and Khan, 2019). Complementing microbiome with humans is established a complex mutualistic host-microbial relationship. The human body provides a suitable living environment for microbes. The microbiome plays a crucial role in the development and normal function of the body, including modulating the immune system, absorbing nutrients and protecting the body (Van de Wiele et al., 2016; Jenmalm, 2017).

With the advent of research, the relationship between the microbiome and inflammation has become increasingly apparent. Moreover, the role of microbiome and inflammation in the occurrence and development of cancer has also been reported by numerous research studies. We hypothesized that when the homeostasis of microorganisms is compromised, the microorganisms themselves or their secretions will cause a series of immune responses in the organism. Persistent inflammation can result in chronic inflammation, which is one of the inducing factors of the tumor. In the presence of chronic inflammation, the organism's susceptibility increases, making the cells prone to cancer. Most studies in cervical cancer have a focus on the relationship between microbiota and cervical cancer, yet inflammation may also be a key driver of cervical cancer. To determine the link between microbiota inflammation and cervical cancer, this review examines how the microbiota profiles, the protective effects of Lactobacillus and the association of microbiota disturbances under inflammation and human papillomavirus (HPV). We also explained the carcinogenic role of the typical cervical microbiome. Finally, probiotic therapy and immunotherapy are discussed.

\section{THE VAGINAL MICROBIAL ENVIRONMENT}

As in the gastrointestinal tract, the female reproductive tract is a habitat for microbes. Most microbes coexist with the body, affecting human health and disease (Foster et al., 2017). Researchers have analyzed the distribution of vaginal microbiome in women of reproductive age by $16 \mathrm{~S}$ rRNA gene sequencing, and hierarchical taxonomic clustering, and they conclude that the vaginal microbiome profile of each woman could be classified into six community state types (CSTs) (Mitra et al., 2016; Brotman et al., 2018). CST-I, II, III, and V are dominated by Lactobacillus crispatus, Lactobacillus gasseri, Lactobacillus iners, and Lactobacillus jensenii, respectively. In contrast, CST-IV, has a low relative abundance of Lactobacillus and high relative abundance of facultative anaerobes, and could be divided into CST IV-A as well as CST IV-B. Streptococcus and Prevotella characterize CST IV-A, and Atopobium accounted for a higher proportion in CST IV-B. Importantly, anaerobic bacteria of CSTIV are commonly associated with bacterial vaginosis (BV). In general, healthy women have one or more Lactobacillus in the vagina, with a small diversity of bacteria (Laniewski et al., 2020).

\section{The Vaginal Microbial Environment of a Healthy Person}

The state of the microbiome is dynamic. The microbiome remains in dynamic balance when the body is healthy, whereas high bacterial diversity and low numbers of lactic acid bacteria indicate a bacterial imbalance or inflammation (Figure 1). Furthermore, many factors are reported to affect the balance of microbiome. On the one hand, epidemiological factors, such as dietary habits, contraception, smoking and sex life, are the contributing factors. On the other hand, social environment factors (sanitary conditions, living area, and socioeconomic) also influence the composition of the microbiome. Most notably, the host's factors are also a kind of factor that cannot be ignored (Audirac-Chalifour et al., 2016; Torres-Poveda et al., 2016). Lactobacillus does not dominate all vaginal microbiome regions in healthy women, possibly due to geographical and socioeconomic influences. In Hispanic women and women of African descent (30-40\%), a non-lactobacillus predominance of the vaginal microbiome is more common (Fettweis et al., 2014; Borgdorff et al., 2017; Laniewski et al., 2018). Meanwhile, in another study of Japanese-ancestry, European-ancestry, and African-ancestry, the vaginal microbiome, dominated by lactic acid bacteria, is more common in Japanese and Caucasians than women of African descent, confirming this phenomenon (Zhou et al., 2010). Interestingly, these areas also tend to have higher cancer prevalence rates than areas where Lactobacillus is the dominant species (Miller et al., 2018), which is the subject of future study. The result may suggest that Lactobacillus is a major defender of the microenvironment protecting the female reproductive tract.

The dynamic balance of the vaginal microbiota could also be affected by the host's hormone or immune system. Due to the effect of estrogen, the vaginal microbiome becomes more volatile during menstruation, relatively stable and less diverse after menstruation (MacIntyre et al., 2015). After menopause, the lack of estrogen in women caused an increase in anaerobic bacteria in the vaginal flora and a decrease in Lactobacillus. The composition of the vaginal microbiota is affected by estrogen, which affects the release of pro-inflammatory cytokines, chemokines, and vaginal antimicrobial peptides (AMPs) (Torcia, 2019). Evidence suggests that when estrogen is elevated, large amounts of glycogen are detected in vaginal epithelial cells. Furthermore, estrogen helps the vaginal epithelium cells to mature and produce $\alpha$-amylase. Glycogen is degraded to produce simple sugars such as maltotriose, maltotetraose, and $\alpha$-dextrins. Consequently, Lactobacillus, which cannot break down glycogen, 


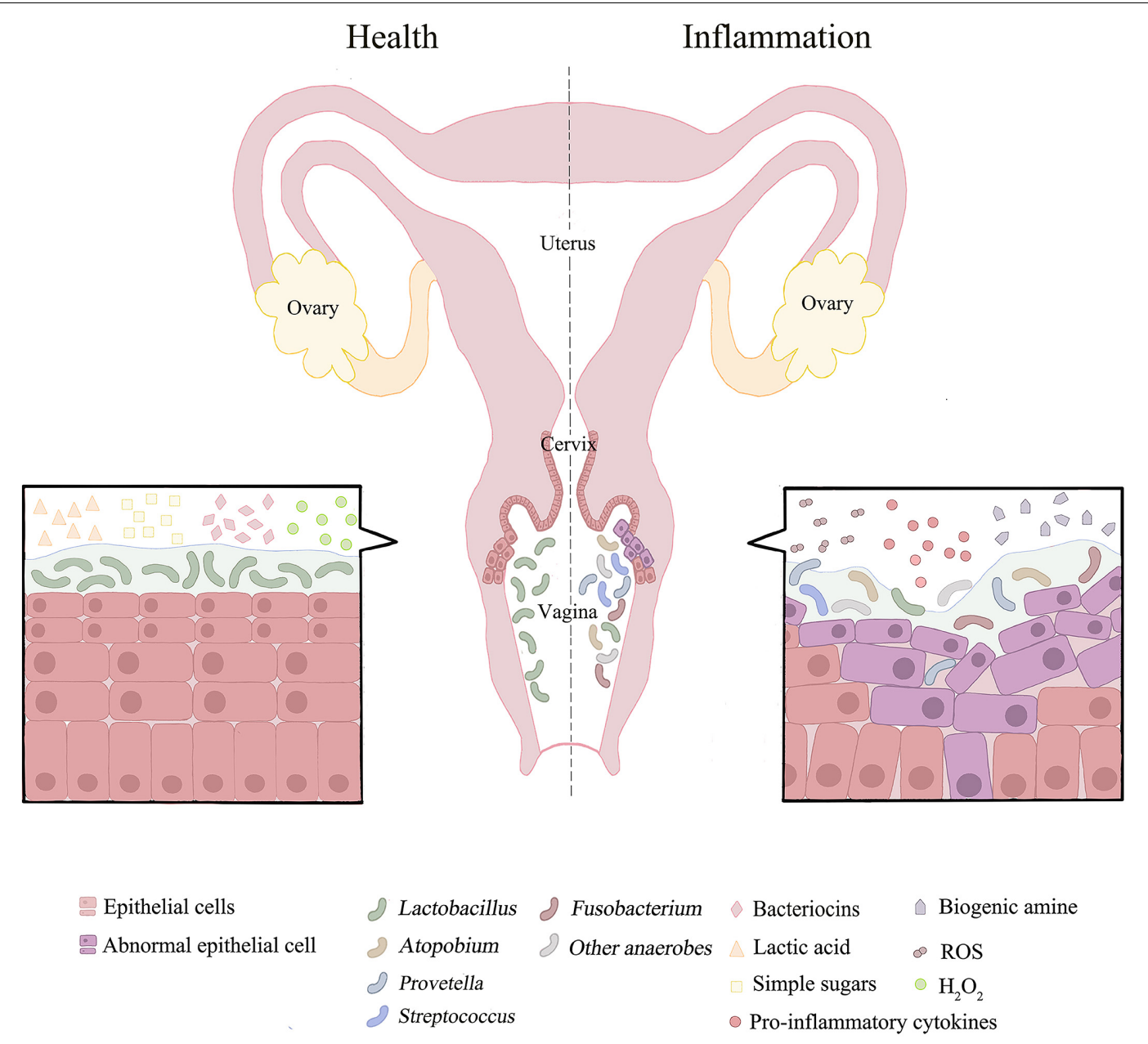

FIGURE 1 | The distribution of vaginal microorganisms in a healthy or inflammatory state. The vaginal microbial environment of healthy people is usually dominated by lactobacillus with high abundance. Lactobacillus depends on glycogen products for growth. Lactic acid, bacteriocins and $\mathrm{H}_{2} \mathrm{O}_{2}$ produced by Lactobacillus may inhibit the growth and development of pathogenic bacteria. When female reproductive tract is in disorder or inflammation, the microbial community is dominated by anaerobic bacteria and has the characteristics of high diversity. This could results in $\mathrm{pH}>4.5$. Simultaneously promote oxidation and nitrification reactions. The associated pro-inflammatory cytokines and ROS are increased, and metabolites in female reproductive tract are converted from lactic acid to biogenic amines. In addition, microbial co-infection can damage epithelial cells and disrupt the mucosal barrier.

relies on glycogen products to grow, forming colonies in the vagina that produce substances such as lactic acid to inhibit the growth of other bacteria (Spear et al., 2014).

\section{The Function of Lactobacillus in the Female Reproductive Tract}

Lactobacillus plays a role in protecting the body and maintaining function in the female reproductive tract or gastrointestinal tract. The composition of the vaginal microbiota may influence local immunity and be involved in the occurrence of cervical cancer and clearance of the HPV. The vaginal microbiota, dominated by various species of Lactobacillus, may play a protective role against opportunistic infections (Audirac-Chalifour et al., 2016). After utilizing those decomposition products of glycogen, Lactobacillus produce lactic acid that keeps the $\mathrm{pH}$ of the vaginal environment below 4.5, and acidizes the mucosal surface (Valenti et al., 2018).
Lactic acid could reduce the cytotoxicity of natural killer cells, induce the secretion of anti-inflammatory cytokine interleukin10 (IL-10), and reduce the production of pro-inflammatory cytokine IL-12 in dendritic cells (Sun et al., 2017). Notably, lactic acid is also produced by cancer cells and identified as a tumor marker (Ilhan et al., 2019). Therefore, the origin of lactic acid and its relationship with cervical cancer remains to be studied. In addition, bacteriocins with antimicrobial properties are also produced from Lactobacillus. Bacteriocins, a class of AMPs, are widely found in living organisms. It cannot only resist the invasion of pathogenic microorganisms through direct bactericidal action, but also mediate the acquired immune response and regulate the inflammatory immune response. Its cytotoxicity and cell lysis activity plays an important role in antitumor activity. Furthermore, a healthy vaginal microbiota is also associated with elevated defensins, and a previous study found a significant decrease in AMPs levels in patients with BV compared 
to healthy women (Al-Nasiry et al., 2020). Apart from vaginal AMPs, other substances can improve the vaginal defense system. IgA and IgG neutralize the effects of pathogenic microorganisms at the site of infection, preventing them from binding to the vaginal epithelium and ingesting nutrients. Mannose-binding lectin (MBL) may also protect against vaginal invasion and infection. These metabolites could resist the adhesion and growth of other bacteria in the vaginal epithelium. Furthermore, Lactobacillus compete with pathogens by acquiring nutrients and occupying territories, thus act as repellents and preventing pathogens from adhering to the vaginal epithelium (MaldonadoBarragan et al., 2016). Another study report that the complement system would be activated by Lactobacillus that sticks to the vaginal epithelium. The consequence could be triggering the body's defenses. When the bacteria absorb nutrients and attach to the cell's epithelium, the immune system is activated, further controlling microbial growth (Chase et al., 2015; Laura et al., 2016). As mentioned, Lactobacillus is a significant factor that maintains the health of the female reproductive tract, and the lack of Lactobacillus may promote the overflow of several anaerobic bacteria associated with sexual transmission. Cervical lesions could be caused by these anaerobic bacteria.

\section{The Particularity of Dysregulation of Vaginal Microbial Environment}

Notably, numerous data point out that not all Lactobacillus can protect the health of the female reproductive tract and the stability of the vaginal microbial environment. Unlike other Lactobacillus, L. iners are often found in communities where nonLactobacillus are predominant (Gajer et al., 2012). L. crispatus appears to be the most protective lactic acid bacterium for host health, but several evidence suggest that L. iners is associated with disease (Oh et al., 2015; Kyrgiou et al., 2017), and L. iners are also found in women with vaginal microbial environment disorders caused by HIV, HPV, and HSV-2 (Borgdorff et al., 2014; van de Wijgert et al., 2014). Previous studies have found that the possible reason for $L$. iners association with diseases is related to $\mathrm{H}_{2} \mathrm{O}_{2}$ (Mitra et al., 2015; Laura et al., 2016). $\mathrm{H}_{2} \mathrm{O}_{2}$ is considered to be produced by $L$. crispatus rather than $L$. iners. The vaginal microbiota with $L$. crispatus that is the dominant bacteria is the most stable. This microbiome rarely causes infections. L. crispatus produces both D-lactic acid and L-lactic acid, but $L$. iners produces only L-lactic acid (Amabebe and Anumba, 2018).

D-lactic acid is only a bacterial product, while L-lactic acid is a bacterial product also produced by vaginal epithelial cells and bacteria (Witkin et al., 2013). High concentrations of D-lactic acid inhibit chlamydia infection due to the $\mathrm{pH}$ dependent effects of the vaginal microenvironment (Witkin et al., 2013). Chlamydia infection can promote the persistence of HPV infection, which will be discussed later. D-lactic acid also prevents upper reproductive tract infections by regulating the production of extracellular matrix metalloproteinase inducer (EMMPRIN) in vaginal epithelial cells induced by L-lactic acid and inhibiting the production of matrix metalloproteinase-8 (MMP-8) (AlvarezOlmos et al., 2004). In addition, vaginal $\alpha$-amylase is associated with levels of D-lactic acid and other vaginal epithelial AMPs, but not L-lactic acid. The importance of vaginal $\alpha$-amylase was also demonstrated because vaginal $\alpha$-amylase is highest in women without vulvovaginal disease and lowest in women with BV (Nasioudis et al., 2015).

\section{INFLAMMATORY RESPONSE TO DEREGULATION OF VAGINAL MICROBIAL ENVIRONMENT}

As the main defender of the cervicovaginal microenvironment, Lactobacillus maintains the dynamic balance of the entire cervix-vaginal microflora. As mentioned, while the number of Lactobacillus significantly decreased and different anaerobic bacteria gradually dominated, the dynamic balance will be disturbed, leading to the imbalance of cervical and vaginal microorganisms. Mechanistically, increased microbial diversity leads to the augmented production of related pro-inflammatory cytokines and chemokines, which amplify the inflammatory response and increase the number of immune cells recruited (Round and Mazmanian, 2009; Torcia, 2019; Wiik et al., 2019; Norenhag et al., 2020). This phenomenon promotes immune dysregulation in the female reproductive tract, thus providing a suitable site for tumor development (Figure 1; Schwabe and Jobin, 2013). The mixed microbial infection could promote the replication, transcription and modification of $\mathrm{HPV}$, and increase the incidence of cervical cancer.

Additionally, microbial co-infection could increase inflammation and damage epithelial cells (So et al., 2020), which is one of the mechanisms of cervical intraepithelial neoplasia (CIN) (Wiik et al., 2019; Norenhag et al., 2020). Acute inflammation and persistent infection turn into chronic inflammation, which can cause cytotoxic effects on normal cells, damage DNA, and eventually develop into cancer cells, leading to cervical cancer (Balkwill and Mantovani, 2001; Fernandes et al., 2015). The expression of E6 and E7 promoted the inhibition of apoptosis despite the DNA damage in the cells, leading to chromatin abnormalities (Kyrgiou et al., 2017). The microbiota corresponding to the microbiota imbalance of the female reproductive tract and the increase of microbiota diversity is CST-IV, and the female reproductive tract microenvironment dominated by CST-IV is more susceptible than other microbiota. Active microorganisms in the CST-IV microbiome have become a potential risk factor for the occurrence of cervical cancer (Champer et al., 2018). It is noteworthy that microbial metabolites in the cervix and vagina could also be altered by the phenomenon of microbial disorders (Ilhan et al., 2019). For example, with the increase of anaerobic or microaerobic bacteria, the metabolites in the female reproductive tract will change from lactic acid to amines (Nelson et al., 2015; Srinivasan et al., 2015). Glycochenodeoxycholate (GCDC) is a metabolic product of a host-microbial metabolism, which could inhibit the growth of some anaerobic or microaerobic bacteria usually found in bacterial vaginitis and microbiological disorders (Fiorucci and Distrutti, 2015; Ridlon et al., 2016). However, GCDC can induce inflammation and toxicity, and cause carcinogenesis of the host epithelial cells, when the threshold of GCDC concentration is 
exceeded (Tatsugami et al., 2012). Ilhan et al. (2019) showed that the concentration of GCDC was elevated with the failure of Lactobacillus and the continuous presence of inflammatory reactions. All suggest that Lactobacillus is an indispensable guardian of the female reproductive tract.

The occurrence of BV and pelvic inflammation (PID) can be influenced by cervicitis (Klein et al., 2019). Cervicitis is usually caused by infection of non-symbiotic microorganisms that express certain antigens, leading to persistent inflammatory infection, as explained previously (Klein et al., 2020a). It is noteworthy that infections of the vaginal microbial environment may also indirectly affect the development of ovarian cancer by inducing local inflammation and immune regulation.

\section{THE DRIVING EFFECTS OF MICROBIOME ON CERVICAL CANCER}

The microbiota maintains a symbiotic relationship with the host, and the dynamic balance of the microbiota is one of the prerequisites for the organism to maintain health. When the balance of the microbiota is disturbed, the change may harm the health of the host, alter the physiological changes of the individual, and lead to the development of diseases, such as cancer. Previous studies reported that microbiota plays an increasingly significant role in the occurrence and development of cancer (Bhatt et al., 2017; Rajagopala et al., 2017). For instance, Helicobacter pylori invasion of the gastrointestinal tract could induce chronic inflammation, lead to malignant transformation of B cells, and ultimately to gastric adenocarcinoma. Recently, researchers have linked the bacterium $H$. pylori to colorectal tumors (Witkowska and Smolewski, 2013; Shmuely et al., 2014; Ayse et al., 2015). Microbiome dysregulation is often involved in colorectal cancer, and Streptococcus is one of the key drivers. It can not only promote the occurrence of colorectal cancer (Yu et al., 2017), but also affect the recovery of prognosis of colorectal cancer (Mima et al., 2016). There are also significant differences in the composition of the breast cancer microbiome between women with breast cancer and healthy people (Urbaniak et al., 2016). Meanwhile, the researchers found a high abundance of oral symbionts in the lower respiratory tract of lung cancer patients (Tsay et al., 2018). As a rich area of microbes, the female reproductive tract is not surprising that microbe dysregulation exists.

Meanwhile, numerous reports have shown that microbial groups promote cancer by inducing inflammatory reactions in recent years. It has been demonstrated in mice with colorectal tumors that the microorganisms in mice induce the activation of tumor-associated myeloid cells, resulting in increased IL-23 and IL-17 secretion (Grivennikov et al., 2013). The development of endometrial cancer could be accelerated by PID (Yang et al., 2015). Escherichia coli would only cause cancers in the presence of an inflammatory response (Arthur et al., 2014). Although the primary pathogenesis is estrogen overproduction, there is evidence that gut microbes can influence estrogen production to some extent. This may indicate a mechanism where the microbiome in different parts of the body may have a circuit that affects the physiological function of other parts. Taken together, these suggest that the influence of the microbiome on the body's immune system is a mechanism for inflammation-related cancer.

\section{The Imbalance of Cervicovaginal Microorganisms Is the Basic Factor That Induces Inflammation and Cervical Cancer}

Cervicovaginal microbiological disorders have become a key factor in inflammation, HPV infection and cervical cancer. As mentioned earlier, Lactobacillus competes with pathogens for territory in the vaginal epithelium and inhibits the growth and development of pathogens by secreting lactic acid, bacteriocins and $\mathrm{H}_{2} \mathrm{O}_{2}$. An additional benefit of Lactobacillus is that it could also activate the complement system, trigger a local immune response, and further control the pathogen against the organism (Kovachev, 2020). However, in addition to the most beneficial Lactobacillus, other microbes, such as anaerobic bacteria, can regulate the body's immune response when they lose balance. This can illustrate the complex relationship between the female genital tract and cervicovaginal microorganisms. The progression of cervical cancer is related to changes in the composition of the microorganism in the cervix vagina, especially the failure of Lactobacillus and the overgrowth of anaerobic bacteria (Mitra et al., 2015; Audirac-Chalifour et al., 2016). Microbial imbalance is often associated with the decreased abundance of Lactobacillus and the increased quantity of anaerobic bacteria (Mitra et al., 2015; Sodhani et al., 2017). This is a typical characteristic of CST-IV in the microbial spectrum. It is interesting to note that the characteristics of bacterial vaginitis are analogous to the trait of CST-IV (Kovachev, 2020). The conclusion could suggest that bacterial vaginitis and CST-IV are closely linked.

\section{Human Papillomavirus Is a Key Factor in the Development of Cervical Cancer}

Human papillomavirus is known to be a pivotal factor in the development of cervical cancer. HPV causes various diseases, including cervical cancer and precancerous lesions ( $\mathrm{Li}$ et al., 2020). HPV is divided into hr-HPV and lr-HPV. Most of the $\mathrm{HPV}$ entering the female reproductive tract is cleared by the host's immune system (Audirac-Chalifour et al., 2016). Tolllike receptors (TLRs), natural killer cells and other mechanisms may be activated by the host to eliminate HPV (Stanley, 2012). A local innate immune response may mediate the initial host immunity to HPV infection, and acquired immunity mediated by antigen-presenting cells after HPV vaccination can also reduce the infection rate of HPV. However, when the host is subjected to persistent hr-HPV infection, it can develop cervical squamous intraepithelial lesions, and even cervical cancer (Astride et al., 2016). These cancer-related viruses may cause cancer directly by affecting the cellular structure, or indirectly contribute to cancer through immune escape or chronic inflammation (Curty et al., 2019). E6/E7 may disrupt the regulation of gene expression in host cells, leading to abnormal cell proliferation by influencing the control mechanisms of cell cycle and antigen expression, leaving the body unresponsive (Wang et al., 2014; 
Zhang et al., 2015). In addition, the expression of E6/E7 also overexpressed PD-1, thereby inhibiting the activation of T cells (Allouch et al., 2020). The microenvironment of the female reproductive tract changes with the stage of cervical cancer when a woman has cervical cancer. Vaginal acidity and cytokines are also affected by the development of cervical cancer, leading to further local immunosuppression. For instance, the presence of immunosuppressant agents, such as transforming growth factor$\beta 1$ (TGF- $\beta 1$ ) and IL-10, may contribute to HPV persistence. The cervicovaginal microflora can increase the expression of immunosuppressive factors (Kyrgiou et al., 2017). A previous study examines that serum FMS-like tyrosine kinase and tumor necrosis factor- $\alpha$ (TNF- $\alpha$ ) expression are significantly elevated in patients with CST-IV disease compared to the CST-I group (Anahtar et al., 2015).

Human papillomavirus is a major contributor to cervical cancer and its precancerous lesions; however, HPV is not a sufficient condition for cervical cancer (Muñoz et al., 2003). The persistence of HPV infection can be affected in many ways. Imbalanced cervicovaginal microbiota and inflammation contribute to HPV persistence. Various cytokines are produced and damaged by the epithelial intimal barrier that creates optimal conditions for HPV infection (Astride et al., 2016). Persistent infection with HPV in turn impact the dysregulation and inflammation of cervical and vaginal microbiology, because the host's immune defenses could be negatively affected by persistent HPV infection (Klein et al., 2019). A previous study has found that HPV may also affect the mucosal metabolism, and further affect the cervix vaginal microenvironment. When HPV infects the mucosal surface, a series of inflammation-related mechanisms are initiated by HPV, such as the activation of overexpressed macrophages and NK cells, and the activation of local mucosal immunity by pro-inflammatory cytokines (Garcea et al., 2005). HPV infection, bacterial vaginitis and microbiota dysregulation are capable of acting on or influencing each other mutually.

\section{Inflammation Is an Important Driver of Human Papillomavirus Infection and Cervical Cancer}

Chronic or persistent infection with HPV is necessary, but HPV alone is not enough to induce cervical cancer and require additional endogenous or exogenous cues. At the low abundance of Lactobacillus, there is an increased likelihood of dysregulating the cervix vaginal microbiota and an increased risk of bacterial vaginitis, leading to increased production of mucin-degrading enzymes. Meanwhile, the production of $\mathrm{H}_{2} \mathrm{O}_{2}$, lactic acid and other products are reduced because of fewer producers, and the barrier of cervical and vaginal epithelium mucosa becomes more fragile (So et al., 2020). The microflora stimulates the production of pro-inflammatory cytokines that further disrupt the epithelial intimal barrier. A previous survey reported 32 women (ages 38-55) diagnosed with cervical cancer (Kovachev, 2020), to determine whether or not they had suffered from bacterial vaginitis and observed their cervix vaginal microflora. The results showed that $23(71.9 \%)$ patients are affected by a vaginal microbiome disorder. Another study supports the hypothesis that inflammation could contribute to cervical cancer. Elevated inflammatory cytokines are found in the vaginas of patients with cervical cancer or precancerous lesions (Mhatre et al., 2012; Caselli et al., 2020). In 85 patients (32\%), the prevalence of CST-IV is significantly higher than the general population (10.3\%). Meanwhile, compared with patients with CIN2, CST-IV is more common in patients with CIN3 stage. These data illustrate the correlation between the severity of CST-IV and cervical cancer. The study also noted that high concentrations of pro-inflammatory cytokines are found in the vaginal environment of CIN patients. Compared with healthy people, IL- $1 \alpha$, IL-1 $\beta$, IL-6, IL-8, and TNF- $\alpha$ in the vagina of CIN patients are higher. Interestingly, the CST-IV ratio is also higher in these patients with the cervicovaginal microbial spectrum (Di Paola et al., 2017; Gosmann et al., 2017). In Mitra's study, by examining the microbiota of 169 women, they found that the rate of a CST IV vaginal microbiome doubled in women with low-grade squamous intraepithelial lesions (LSIL), tripled in women with highly squamous intraepithelial lesions (HSIL), and quadrupled in women with invasive cancer (Mitra et al., 2015).

Multiple cytokines are involved in developing various tumors, starting with high-risk HPV infected cells, through maladjustment of many pathways (Barbisan et al., 2012). In the innate immune system, TLRs are used to activate inflammatory defense mechanisms and regulate the clearance of immune complexes, but can also lead to chronic inflammation of unhealthy tissues. Therefore, imbalance or disturbance in one part can promote the formation of tumors (Jouhi et al., 2014). Mutated TNF- $\alpha$ can directly lead to cell canceration (Yang et al., 2018). Meanwhile, IL-6, IL-8, IL-1 $\beta$, and other inflammatory cytokines can promote tumor proliferation and the development of cervical cancer (Schäfer et al., 2013; Liu et al., 2020). For example, IL-1 $\beta$ regulates the expression of CCL-2 by activating nuclear factor- $\kappa$-gene binding (NF- $\mathrm{B})$. It was also found that TGF- $\beta$ mediated immune escape by promoting the overexpression of FBP1 gene in NK cells, making NK cells in a state of low activity in tumor microenvironment (Cong et al., 2018).

Abnormal activation of several different signaling pathways is also a factor contributing to the occurrence of cervical cancer. The upstream regulatory regions of some transcription factors, such as NF- $\mathrm{B}$ and signal transducers and activators of transcription 3 (STAT3), contain homeopathic elements associated with carcinogenesis (Gupta et al., 2018). These transcription factors may influence the regulation of the HPV genome (Shukla et al., 2019). Activation of the janus kinase (JAK)/STAT pathway plays an important role in immune escape. STAT3 can not only increase the expression of inhibitory cytokines such as TGF- $\beta$, IL-6, and IL-10, but also promote the aggregation of regulatory $\mathrm{T}$ cells and induce the immunosuppressive microenvironment by inhibiting the maturation of dendritic cells (Yu et al., 2007). E6/E7 oncoprotein expression has been found to promote the expression of STAT3, which in turn inhibits the production of PRb and p53 (Arany et al., 2002; Basukala et al., 2019). In addition, STAT5 is also activated by oncoprotein E7. Interestingly, this is also required 
for HPV31 genome amplification (Hong and Laimins, 2013). NF$\kappa \mathrm{B}$ plays an essential role in immune response, inflammatory effects, viral replication and tumorigenesis (Bonab et al., 2021). Mutations in HPV E6/E7 oncoprotein I B down-regulate NF$\kappa \mathrm{B}$, thereby blocking the immune response. After developing cancer, NF- $\kappa \mathrm{B}$ is reactivated by cytokines released by $\mathrm{M} 2$ macrophages. Dysregulation of NF- $\mathrm{B}$ promotes inflammatory responses, abnormal cell proliferation and differentiation, persistent angiogenesis, avoidance of immune destruction, and even tissue infiltration and metastasis. Interestingly, while E6 induces IL- 6 expression through NF- $\kappa$ B, IL- 6 also promotes STAT3 production and activation. This also demonstrates the phenomenon of pathways in series with each other (Pique et al., 2019).

Of note, oxidative and nitrifying stress is also one of the main mechanisms of inflammation-induced cancer. Some oxygen and nitrogen-related compounds have been linked to inflammationrelated cancer caused by microbes (Kipanyula et al., 2013; Nelson et al., 2015). They can cause abnormal oxidative stress in the microenvironment and inhibit the function of immune cells. A previous study has found that unlike CST with Lactobacillus as the dominant species, CST-IV with anaerobes as the dominant species has a higher concentration of amines (Nelson et al., 2015). These anaerobic bacteria can increase the level of biogenic amine production. Biogenic amines not only lead to nitrosamine production but also improve the resistance of pathogens to hostmediated defense systems. Additionally, biogenic amines have been found to promote biofilm formation in some pathogens. Certain species of Lactobacillus prevent the colonization of bacteria that produce high levels of amines. Lactobacillus could also remove the carcinogens of these amines and provide an extra layer of protection. This is because Lactobacillus is the dominant species in the cervicovaginal microbiological community type of amines less reason. In addition, Lactobacillus has a cytotoxic effect on cervical cancer cells, preventing the development of cervical cancer (Kyrgiou et al., 2017). Interestingly, inhibition of glucose metabolism could significantly reduce the clearance capacity of helper T cells (Choi et al., 2018). Cancer cells can also drive metabolic changes that suppress immune responses (Bader et al., 2020). These suggest that immune response is related to metabolic pathways, and immune metabolism may be a new way to treat tumors.

Human papillomavirus infection, inflammation and microbiome dysregulation interact or influence each other. We respectively summarized the mechanism of changes in the reproductive tract microenvironment under the conditions of Lactobacillus-dominated vaginal microbial environment and cervical and vaginal microbiota disorders, as shown in Figures 2, 3.

\section{Carcinogenic Effects of Microorganisms}

An increase in certain bacterial or microbial diversity may serve as a biomarker for cervical changes to identify the risk of persistent hr-HPV infection, CIN, and even cervical cancer (Norenhag et al., 2020). Recently, the CST-IV microflora spectrum has become a potential risk factor for cervical cancer (Torcia, 2019). One of the dominant anaerobes is carcinogenic, such as Gardnerella, Sneathia, Fusobacterium spp., and Atopobium vaginae (Drago et al., 2016; Brotman et al., 2018). High levels of Gardnerella, A. vaginae, and Sneathia spp. were most common among women who are persistently infected with hr-HPV for 1 year. Moreover, these bacteria are the common anaerobic bacteria in BV. Interestingly, in addition to these anaerobic bacteria, L. iners is also abundant (Di Paola et al., 2017). Large amounts of $A$. vaginae are inversely associated with HPV (Brotman et al., 2018). In addition, some studies have found that high concentrations of Sneathia spp. and Fusobacterium spp. are found in the genital tract environment of patients with the squamous intraepithelial disease and cervical cancer. In the meantime, mycoplasma and chlamydia have also entered the research field, and increasing numbers of reports have found a link between them and persistent HPV infection.

\section{Fusobacterium spp.}

Fusobacterium spp. has been discovered in colorectal cancer. The proinflammatory expression patterns are reported in colorectal tumors in the presence of high Fusobacterium spp. abundance (Kostic et al., 2013). This may indicate that microbe-induced inflammation is a mechanism that leads to cancer. Furthermore, Fusobacterium spp. could promote the development of dysplasia (Norenhag et al., 2020). This showed that a strong link between gut microbiome populations and colorectal cancer (Viaud et al., 2013). It is possible to guess that the cervix vaginal microbiota may be linked to cervical cancer in the same manner. It has been reported that Fusobacterium spp. is often found in the female reproductive tract (Sommer et al., 2017). In the Korean twin cohort, Fusobacterium spp. serves as a microbial marker to observed HPV infection. In addition, the cytokine profile showed that the local levels of interleukin-4 (IL-4) and TGF$\beta 1$ were significantly increased in the cervix vaginal microflora dominated by Fusobacterium spp. in a Lactobacillus deficiency, and high mRNA levels of TGF- $\beta 1$, IL-4, and IL-10, which was also found in cervical biopsies from patients with the squamous intraepithelial disease and cervical cancer (AudiracChalifour et al., 2016). Another study demonstrates that IL-4 levels are elevated in the presence of Fusobacterium spp. infection (Vielot et al., 2015). Fusobacterium may be involved in an immunosuppressive microenvironment characterized by antiinflammatory cytokines. This indicates that Fusobacterium spp. plays a certain role in the occurrence of cervical cancer, and further research is needed to determine whether there is a new influencing mechanism.

\section{Mycoplasma genitalium}

The Mycoplasma family consists of the genera Mycoplasma urealyticum and several relatively common sexually transmitted species, such as Mycoplasma hominis and Mycoplasma genitalium. They are associated with cervical inflammation (Astride et al., 2016; Mitra et al., 2016; Klein et al., 2020b).

The common mycoplasmas that infect the female genital tract are $M$. genitalium and $M$. hominis. Interestingly, they are commonly found as non-symbiotic bacteria in patients with cervicitis and bacterial vaginitis (Klein et al., 2019). Klein's team found that $M$. genitalium can infect epithelial cells, causing a 


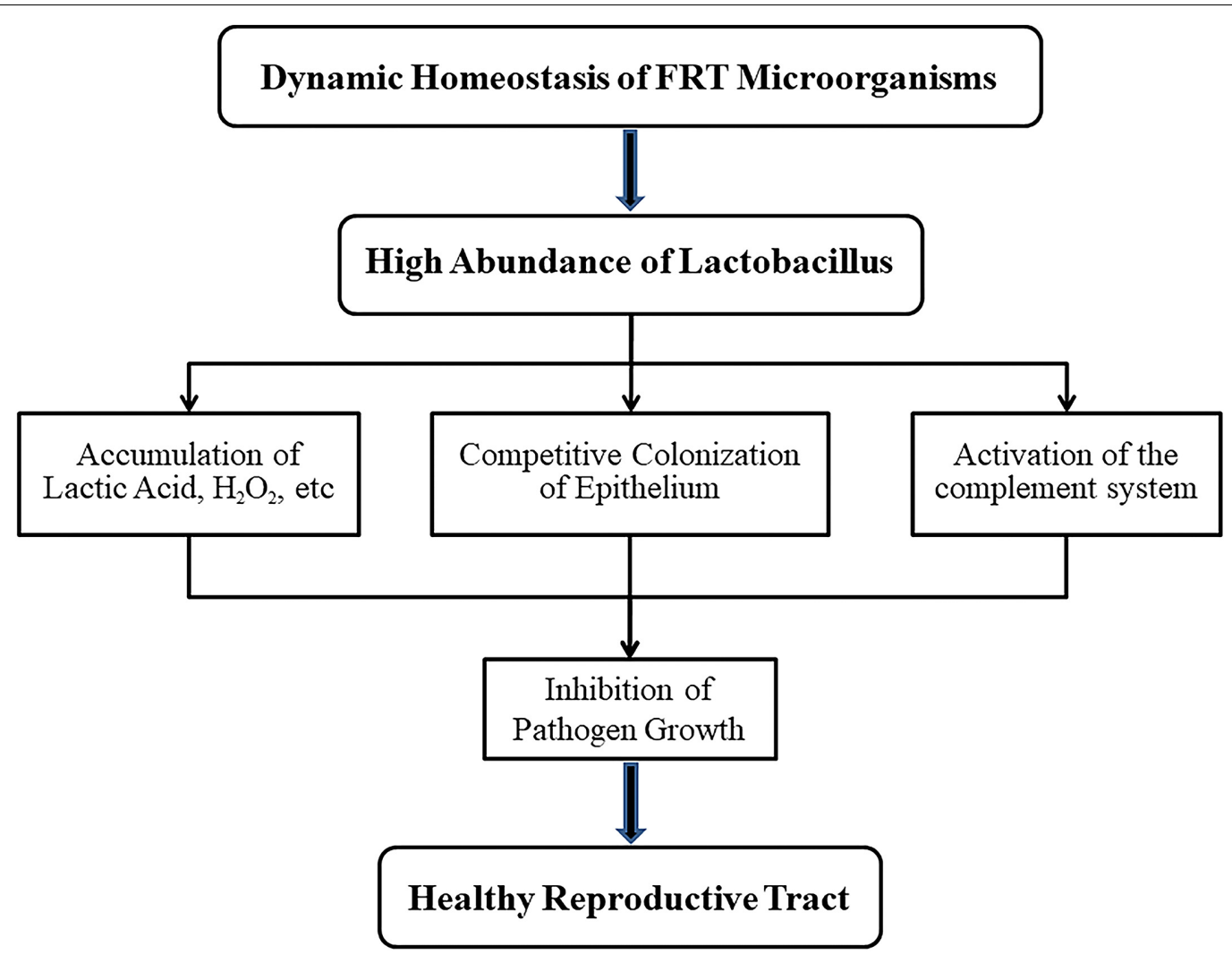

FIGURE 2 | Mechanisms of lactobacillus maintaining health for female reproductive tract (FRT). When the microbial community of female reproductive tract is in dynamic balance, lactobacillus with high abundance will not only produce lactic acid, $\mathrm{H}_{2} \mathrm{O}_{2}$ and other products but also compete with anaerobic bacteria for vaginal epithelial cells. In addition, the complement system could be activated by lactobacillus. These features prevent the growth of pathogens and thus ensure the health of the host.

series of intracellular infections and breaking tight junctions, leading to bacterial vaginitis and cervicitis, and increases the incidence of cervical lesions (Klein et al., 2019). In addition, some studies have confirmed that $M$. genitalium is an independent pathogenic microorganism leading to cervicitis (Taylorrobinson and Jensen, 2011; Ye et al., 2018). This may indicate that in the case of HPV infection, Mycoplasma can cause infect both the cell inside and outside. Other studies have shown that infection of M. genitalium induces chromosomal lesions in cells, which may lead to cancerous cells, especially under chronic inflammation (Verteramo et al., 2009).

The relationship between Mycoplasma and cervical lesions has been gradually discovered, and some scholars have conducted epidemiological studies on them. However, the mechanism between Mycoplasma and cervical cancer is rarely explored. Further studies on the molecular mechanism are needed in the future.

\section{Chlamydia trachomatis}

Chlamydia trachomatis (CT) is the most prevalent sexually transmitted infection (STI) worldwide. Lv et al. (2019) reported that CT-positive women had an approximately four-fold higher risk of hr-HPV infection than those who were CT-negative. This suggests that CT may increase the susceptibility of the cervical gland to HPV. Besides, other studies have found that $C T$ infection can prolong the persistence of HR-HPV infection to the cervix (Verteramo et al., 2009; Silva et al., 2014; Vielot et al., 2015). This further supports the association between CT and HPV. Escarcega-Tame et al. (2020) also found that among women with high levels of CIN, the prevalence of CT was 47 percent higher than in healthy women.

Chlamydia trachomatis infection can damage the cervical mucosal barrier and allow hr-HPV to infect the cervical epithelium through its own entrance (Erika et al., 2005; Paavonen, 2012). Meanwhile, CT could also induce chronic inflammation and affect local and cellular immunity of the cervix. This inhibits the ability of an organism to clear HPV. In addition, several studies have documented that $C T$ infection leads to overexpression of the E6/E7 oncogene of HPV (Paavonen, 2012). Interestingly, cervical lesions could be promoted by $C T$ and HPV through co-infection. CT and HPV may alter cell-tocell adhesion and differentiation by inducing the expression of pro-inflammatory mediators. Silva et al. (2014) found that CTinfected cervical cancer cell lines were found to secrete more pro-inflammatory cytokines. At the same time, CT may enhance HPV activity (Fischer, 2002).

There is a lack of studies on the effect of non-bacterial components (Chlamydia, Mycoplasma, fungal, and non-HPV 


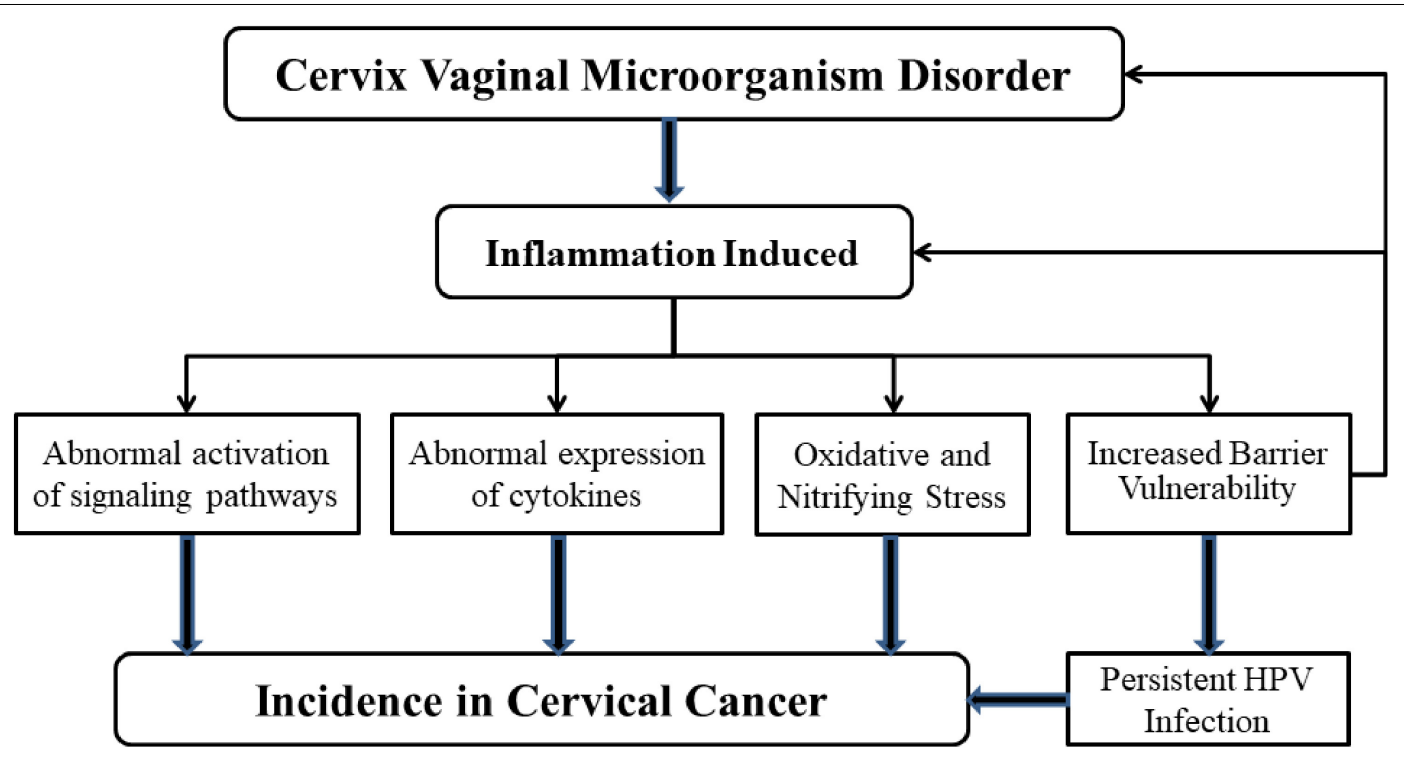

FIGURE 3 | Mechanisms of microbial dysregulation and inflammation leading to cervical cancer. When the balance of microbial environment of female reproductive tract is upset, the inflammatory response is activated. $\mathrm{H}_{2} \mathrm{O}_{2}$, the amount of lactic acid decreases because of the increase in the number of anaerobic bacteria. At the same time, the production of a large number of pro-inflammatory cytokines affects the protective ability of the mucosal epithelial barrier. These phenomena can increase the likelihood of persistent HPV infection, which can lead to cervical cancer. Abnormal expression of cytokines and abnormal activation of signal pathways also lead to the occurrence of cervical cancer. It is important to note that the presence of HPV could also influence microbial homeostasis and the activation of inflammation-related mechanisms.

viruses) on cervical cancer, which may be a direction worth exploring. In recent years, some reports have also found that they may affect the progression of cervical cancer (Liang et al., 2019; Stelzle et al., 2021; Subramaniam et al., 2021).

\section{Gut Microbiomes}

The intestinal microbiome can indirectly affect the abundance of Lactobacillus in the cervix vaginal microenvironment by regulating the release of estrogen (Romero et al., 2014; Jespers et al., 2017). This may lead to a new concept, the gut-vaginal axis (Baker et al., 2017). Some microorganisms in the human intestine can affect the secretion and transport of estrogen. They secrete $\beta$-glucuronidase and $\beta$-glucosidase. These products bind to estrogen in the liver and promote its reabsorption into the circulation (Plottel and Blaser, 2011; Flores et al., 2012). Free estrogen is sent to the distal sites, including the female reproductive tract. It binds to receptors and triggers a cascade of intracellular signaling that triggers glycogen production and thickens the genital epithelium and produces mucus. Before menopause, estrogen levels drop dramatically before menstruation and the Lactobacillus in the vaginal microbiome collapse (Mirmonsef et al., 2016; Muhleisen and HerbstKralovetz, 2016; Nunn and Forney, 2016). When Lactobacillus concentrations are too low, anaerobic bacteria become the dominant bacteria in the vaginal microenvironment contributing to the development of cervical cancer. Gut microbes regulate the enterohepatic circulation of estrogen. Their circulatory effects can be felt throughout the body, such as the cervix and the mammary glands (Goedert et al., 2015; van der Meulen et al., 2016). A previous study has found that cervical cancer patients have a unique gut microbiome (Wang et al., 2019). In addition, a lack of estrogen may also cause vaginal atrophy. Both are thought to be responsible for increasing bacterial diversity (Brotman et al., 2018).

\section{Other Microbiome}

Gardnerella vaginalis may be involved in biofilm formation, contributing to the persistence of HPV infection (Swidsinski et al., 2014; António and Nuno, 2015). Berggrund et al. (2020) studied the relationship between the cervix vaginal microflora and the course of HPV-16 infection. They found that G. vaginalis and A. vaginae were associated with CIN (Curty et al., 2017; Di Paola et al., 2017; Godoy-Vitorino et al., 2018; Berggrund et al., 2020). A high abundance of Atopobium spp., in the cervix vaginal microflora, may be one of the critical markers of cervical lesions (Seo et al., 2016). Atopobium spp. is highly specific for BV. Similar to Gardnerella, the enrichment of Atopobium spp. is also related to CIN3 to some extent (Brusselaers et al., 2019). A. vaginae can activate pro-inflammatory transcription factor$\kappa \mathrm{B}$ (NF-кB), TNF- $\alpha$, IL-6, and IL-8 (Doerflinger et al., 2014). In addition, patients with squamous intraepithelial disease tend to have high levels of Sneathia spp. in the female reproductive tract (Audirac-Chalifour et al., 2016).

\section{TREATMENT OF CERVICAL CANCER}

Surgery, chemotherapy and radiotherapy can cure more than $90 \%$ of women with early cervical cancer; however, there are still cancer recurrences or metastasis. Many efforts have been made to develop new drugs to treat cervical cancer. 
TABLE 1 | Therapeutic potential of probiotics based on microbiome and inflammatory in cervical cancer.

\begin{tabular}{|c|c|c|c|}
\hline & Mechanism & In vitro/vivo & References \\
\hline Lacticaseibacillus Paracasei Shirota & Improving HPV clearance & In vivo & Verhoeven et al., 2013 \\
\hline Lacticaseibacillus casei & Improving HPV clearance & In vivo & Verhoeven et al., 2013 \\
\hline Bacteroides fragilis & Improving the effectiveness of CTLA-4 targeted immunotherapy & In vivo & Motevaseli et al., 2013a \\
\hline Lactobacillus gasseri & Presenting cytotoxic effect in HeLa cell & In vitro & Motevaseli et al., 2013b \\
\hline Lactobacillus crispatus & Presenting cytotoxic effect in HeLa cell & In vitro & Motevaseli et al., 2013b \\
\hline Lacticaseibacillus rhamnosus & Increasing NK cell activity & In vivo & Bermúdez-Humarán et al., 2011 \\
\hline Bifidobacterium lactate & Increasing NK cell activity & In vivo & Dallal et al., 2012 \\
\hline Lactococcus lactis & Producing E7 antigen & In vivo & Bermúdez-Humarán et al., 2011 \\
\hline
\end{tabular}

\section{Probiotic Therapy}

Probiotics are made up of living bacteria such as Bifidobacterium, Lactobacillus, and Streptococcus. It reduces the risk of certain cancers by regulating the composition of the microbiome and increasing inflammation (Li et al., 2020).

Probiotics containing Lacticaseibacillus Paracasei Shirota or Lacticaseibacillus casei can significantly improve HPV clearance (Verhoeven et al., 2013). In addition, Bacteroides fragilis can also improve the effectiveness of CTLA-4 targeted immunotherapy. The combination of $L$. gasseri and $L$. crispatus has shown in vitro cytotoxic effects on HeLa cervical cancer cells (Motevaseli et al., 2013a,b). Interestingly, milk consumption containing Lacticaseibacillus rhamnosus and Bifidobacterium lactate increased NK cell activity, and some Lactobacillus also stimulated the production of cytokines such as TNF- $\alpha$ and $\gamma$-IFN, which in turn increased immune cell activity (BermúdezHumarán et al., 2011; Dallal et al., 2012; Shin et al., 2016; Pique et al., 2019). Intranasal administration of recombinant Lactococcus lactis expressing E7 antigen can also induce the body to produce antibodies to E7, thus initiating specific immunity (Bermúdez-Humarán et al., 2011; Carse et al., 2021). We summarized the probiotic, in vivo and vitro development and mechanism in Table 1, providing a reference for readers.

\section{Immunotherapy}

Immunity is a kind of self-protection system of the body, which plays an important role in protecting the body against infections. The importance of immune checkpoints is highlighted. PD-1 receptor, the mediator of immune checkpoint, also plays a vital role in developing tumor. Typically, the PD-1 pathway regulates specific immunity, which in turn prevents cells from becoming cancerous (Allouch et al., 2020). When the PD-1/PD-L1 pathway is activated, $\mathrm{T}$ cell receptor signal transduction is inhibited and $\mathrm{T}$ cell activity is significantly weakened. Therefore, PD-1 mab drugs have been used clinically to specifically block the binding between PD-L1 and PD-1, reactivate the activity of T cells, and then kill tumor cells (Riley, 2009). The use of PD-1 mab drugs has also been approved by the FDA and is already being used to treat advanced cervical cancer. In addition, some STAT3 or NF- $\kappa \mathrm{B}$ inhibitors are in pre-clinical development (Pakish and Jazaeri, 2017). However, due to high toxicity, the development of these inhibitors in tumor therapy has been slow. Therefore, many studies have focused on regulating upstream pathway targets to inhibit STAT3 or NF- $\mathrm{kB}$ activation. At present, there are clinical treatment options for IL-6 expression (Johnson et al., 2018). Proteasome inhibitors that block IкB have also been found to reduce NF- $\kappa \mathrm{B}$ phosphorylation and treat multiple myeloma (Vrabel et al., 2019).

\section{CONCLUSION AND FUTURE PERSPECTIVES}

Microorganisms maintain a symbiotic relationship with the host. The host provides a suitable environment for the microorganism, and they can regulate the body function of the host to a certain extent. Opportunistic pathogens, or pathogens, trigger a series of reactions that can infect the body and even lead to cancer when the balance between the microbe and the host is disrupted. Additionally, with the deepening of research, an increasing number of studies have found that microorganisms can cause local inflammatory reactions, thus increasing the susceptibility of the body and the risk of cancer. In the female reproductive tract, the role of Lactobacillus has become prominent, and when the dynamic balance of the microbial environment is upset, the negative effects of anaerobic bacteria will counteract the positive effects of Lactobacillus. How to maintain the dynamic balance is something to consider.

Microbial dysregulation also results in the release of a large number of pro-inflammatory cytokines and chemokines, resulting in a local inflammatory response. The link between vaginal microbes and cancer has also been widely investigated. Some studies have also shown that lactic acid bacteria have cytotoxic effects on cervical cancer cells. The effects of Mycoplasma and Chlamydia on the body should also be explored. Some of it may be in the body itself, but there is also the possibility that conditions can cause disease. If it is an exogenous substance, it is more important to consider whether the immune system of the body can remove it.

The effect of intestinal microbes on cervical cancer is worth discussing. In cervical cancer, gut microbes have been found to regulate the release of estrogen. However, the role of intestinal microbes in tumor regulation is more elaborate. The tumor microenvironment is simultaneously regulated by immune cells, related pathways, and chemokines, and gut microbes have been found to influence the expression of inflammation-related pathways. When intestinal microbes are imbalanced, it also inhibits immune monitoring to a certain extent. The type of 
gut microbiome can block the $\mathrm{PD}-1 / \mathrm{PD}-\mathrm{L} 1$ pathway, and thus the composition of gut microbiome can determine the clinical response of patients to immune checkpoint inhibitors (Vétizou et al., 2015; Routy et al., 2018; Tanoue et al., 2019). Interestingly, intestinal microbes can also play a certain regulatory role in other cancers, even neurological diseases, so it is also worth discovering whether microbes from other parts of the body, such as breast and lung, can significantly impact cervical cancer. In conclusion, microorganisms are potential targets for mediating tumor therapeutic efficacy. The use of probiotics, customized oral microbial cocktail tablets, may be an effective option and development direction for treating cervical cancer, and even other cancers.

Human papillomavirus is believed to be a critical driving factor in the development of cervical cancer. The infection process and signaling pathway of HPV have been well studied. These studies provide different ideas and directions for the treatment of cervical cancer. It is also essential to identify reliable biomarkers for the diagnosis of cervical cancer. NF- $\kappa \mathrm{B}$ is known to mediate the physiological function of the immune response and the innate immunity after infection. Inhibition of NF- $\kappa$ B may also inhibit the anti-tumor effect of the immune system balance. Therefore, the balance between the two needs to be considered. Different members of the STAT family may also combine to form heterodimers, which may also play an important role in the immune system of the body. It is worth studying how the balance of STAT family members influences tumor progression or immunity.

Inflammation is not always caused by infection, but infection and other foreign substances entering the body often cause inflammation. However, inflammation is a quick fix, not a final solution. Clearing the cause still requires precise, antigen-specific adaptive immunity compared to innate immunity. Unfortunately, immune recognition is based on specific antigens. With the interference of foreign substances or some abnormal expression of cytokines, the immune system may not recognize all the different cells in the primary site. This is also why HPV or cervical cancer cells achieve immune escape. All direct therapies against cancer, including surgery, radiotherapy and chemotherapy, must involve immunity for

\section{REFERENCES}

Adak, A., and Khan, M. R. (2019). An insight into gut microbiota and its functionalities. Cell Mol. Life Sci. 76, 473-493. doi: 10.1007/s00018-018-2943-4

Allouch, S., Malki, A., Allouch, A., Gupta, I., Vranic, S., and Al Moustafa, A. E. (2020). High-risk HPV oncoproteins and PD-1/PD-L1 interplay in human cervical cancer: recent evidence and future directions. Front. Oncol. 10:914. doi: 10.3389/fonc.2020.00914

Al-Nasiry, S., Ambrosino, E., Schlaepfer, M., Morre, S. A., Wieten, L., Voncken, J. W., et al. (2020). The interplay between reproductive tract microbiota and immunological system in human reproduction. Front. Immunol. 11:378.

Alvarez-Olmos, M. I., Barousse, M. M., Rajan, L., Van Der Pol, B. J., Fortenberry, D., Orr, D., et al. (2004). Vaginal lactobacilli in adolescents: presence and relationship to local and systemic immunity, and to bacterial vaginosis. Sex Transm. Dis. 31, 393-400. doi: 10.1097/01.olq.0000130454.83883.e9

Amabebe, E., and Anumba, D. O. C. (2018). The vaginal microenvironment: the physiologic role of Lactobacilli. Front. Med. 5:181. doi: 10.3389/fmed.2018. 00181 achieving sustained efficacy. Inflammation is the leading cause of cancer, and the mechanism between immunity and cancer deserves further study.

Although the biology of various tumors differs, there are some common causes of clinical symptoms. In these cancers, such as gastric adenocarcinoma, colon cancer, and rectal cancer, imbalances of microorganisms are believed to cause chronic inflammation. Ineffective immune responses that fail to clear infections can lead to immune tolerance, which fosters cancer growth. The reality today is immunotherapy is often used as a last resort. We believe that ensuring that specific immunity is not suppressed is the basis of immunotherapy and should be used throughout the whole process.

As compiled above, we should focus on microorganisms and inflammation as two crucial factors in detecting cervical lesions, which may effectively treat cervical cancer.

\section{AUTHOR CONTRIBUTIONS}

Z-WZ contributed to the conception and overall idea of the study and completed the manuscript. YC, H-ZL, D-DW, and H-YL helped in searching for related articles. H-ZL, YC, H-YL, D-DW, and L-CG revised the manuscript. All authors contributed to the article and finally the submitted version is approved by L-CG.

\section{FUNDING}

This work was supported by Science and Technology Key Program of Hunan Province Grants (2016SK2066), Key Projects of Hunan Health Committee (B2017207), Hunan Province Chinese Medicine Research Program (Grant 201940), Changsha City Science and Technology Program (Grant kq1801144), Changsha Central Hospital Affiliated to University of South China Foundation of Key Program (YNKY201901), Hunan Province Foundation of High-Level Health Talent (225 Program), Science and Technology Key Program of Hunan Provincial Health Committee (20201904), and Natural Science Foundation of Hunan Province (2021JJ30753).

Anahtar, M. N., Byrne, E. H., Doherty, K. E., Bowman, B. A., Yamamoto, H. S., Soumillon, M., et al. (2015). Cervicovaginal bacteria are a major modulator of host inflammatory responses in the female genital tract. Immunity 42, 965-976. doi: 10.1016/j.immuni.2015.04.019

António, M., and Nuno, C. (2015). Influence of biofilm formation by Gardnerella vaginalis and other anaerobes on bacterial vaginosis. J. Infect. Dis. 212, 18561861. doi: 10.1093/infdis/jiv338

Arany, I., Grattendick, K. G., and Tyring, S. K. (2002). Interleukin-10 induces transcription of the early promoter of human Papillomavirus type 16 (HPV16) through the $5^{\prime}$-segment of the upstream regulatory region (URR). Antiviral Res. 55, 331-339. doi: 10.1016/S0166-3542(02)00 070-0

Arthur, J. C., Gharaibeh, R. Z., Mühlbauer, M., Perez-Chanona, E., Uronis, J. M., McCafferty, J., et al. (2014). Microbial genomic analysis reveals the essential role of inflammation in bacteria-induced colorectal cancer. Nat. Commun. 5, 4724-4724. doi: 10.1038/ncomms5724

Astride, A. C., Kirvis, T. P., Margarita, B. R., Juan, T. S., Jesús, M., Bernardo, C. C., et al. (2016). Cervical microbiome and cytokine profile at various stages 
of cervical cancer: a pilot Study. PLoS One 11:e0153274. doi: 10.1371/journal. pone. 0153274

Audirac-Chalifour, A., Torres-Poveda, K., Bahena-Roman, M., Tellez-Sosa, J., Martinez-Barnetche, J., Cortina-Ceballos, B., et al. (2016). Cervical microbiome and cytokine profile at various stages of cervical cancer: a pilot study. PLoS One 11:e0153274.

Bader, J. E., Voss, K., and Rathmell, J. C. (2020). Targeting metabolism to improve the tumor microenvironment for cancer immunotherapy. Mol. Cell. 78, 10191033. doi: $10.1016 /$ j.molcel.2020.05.034

Baker, J. M., Al-Nakkash, L., and Herbst-Kralovetz, M. M. (2017). Estrogen-gut microbiome axis: physiological and clinical implications. Maturitas 103, 45-53. doi: 10.1016/j.maturitas.2017.06.025

Balkwill, F., and Mantovani, A. (2001). Inflammation and cancer: back to virchow? Lancet 357, 539-545. doi: 10.1016/s0140-6736(00)04046-0

Barbisan, G., Perez, L. O., Contreras, A., and Golijow, C. D. (2012). TNF-alpha and IL-10 promoter polymorphisms, HPV infection, and cervical cancer risk. Tumour Biol. 33, 1549-1556. doi: 10.1007/s13277-012-0408-1

Basukala, O., Mittal, S., Massimi, P., Bestagno, M., and Banks, L. (2019). The HPV18 E7 CKII phospho acceptor site is required for maintaining the transformed phenotype of cervical tumour-derived cells. PLoS Pathog. 15:e1007769. doi: 10.1371/journal.ppat.1007769

Berggrund, M., Gustavsson, I., Aarnio, R., Lindberg, J. H., Sanner, K., Wikstrom, I., et al. (2020). Temporal changes in the vaginal microbiota in self-samples and its association with persistent HPV16 infection and CIN2. Virol. J. 17:147. doi: 10.1186/s12985-020-01420-z

Bermúdez-Humarán, L. G., Kharrat, P., Chatel, J.-M., and Langella, P. (2011). Lactococci and lactobacilli as mucosal delivery vectors for therapeutic proteins and DNA vaccines. Microb. Cell Fact. 10, 1-10. doi: 10.1186/1475-2859-10S1-S4

Bhatt, A. P., Redinbo, M. R., and Bultman, S. J. (2017). The role of the microbiome in cancer development and therapy. CA Cancer J. Clin. 67, 326-344. doi: 10. 3322/caac. 21398

Bonab, F. R., Baghbanzadeh, A., Ghaseminia, M., Bolandi, N., Mokhtarzadeh, A., Amini, M., et al. (2021). Molecular pathways in the development of HPVinduced cervical cancer. EXCLI J. 20:320. doi: 10.17179/excli2021-3365

Borgdorff, H., Tsivtsivadze, E., Verhelst, R., Marzorati, M., Jurriaans, S., Ndayisaba, G. F., et al. (2014). Lactobacillus-dominated cervicovaginal microbiota associated with reduced HIV/STI prevalence and genital HIV viral load in African women. ISME J. 8, 1781-1793. doi: 10.1038/ismej.2014.26

Borgdorff, H., van der Veer, C., van Houdt, R., Alberts, C. J., de Vries, H. J., Bruisten, S. M., et al. (2017). The association between ethnicity and vaginal microbiota composition in Amsterdam, the Netherlands. PLoS One 12:e0181135. doi: 10.1371/journal.pone.0181135

Brotman, R. M., Shardell, M., Gajer, P., Fadrosh, D., Chang, K., Silver, M. I., et al. (2018). Association between the vaginal microbiota, menopause status, and signs of vulvovaginal atrophy. Menopause 25, 1321-1330. doi: 10.1097/GME. 0000000000001236

Brusselaers, N., Shrestha, S., van de Wijgert, J., and Verstraelen, H. (2019). Vaginal dysbiosis and the risk of human Papillomavirus and cervical cancer: systematic review and meta-analysis. Am. J. Obstet. Gynecol. 221, 9.e18-18.e18. doi: 10. 1016/j.ajog.2018.12.011

Carse, S., Bergant, M., and Schafer, G. (2021). Advances in targeting HPV infection as potential alternative prophylactic means. Int J Mol Sci. 22:2201. doi: 10.3390/ ijms22042201

Caselli, E., D’Accolti, M., Santi, E., Soffritti, I., Conzadori, S., Mazzacane, S., et al. (2020). Vaginal microbiota and cytokine microenvironment in hpv clearance/persistence in women surgically treated for cervical intraepithelial neoplasia: an observational prospective Study. Front. Cell Infect. Microbiol. 10:540900. doi: 10.3389/fcimb.2020.540900

Castellon, X., and Bogdanova, V. (2016). Chronic inflammatory diseases and endothelial dysfunction. Aging Dis. 7, 81-89. doi: 10.14336/AD.2015.0803

Champer, M., Wong, A. M., Champer, J., Brito, I. L., Messer, P. W., Hou, J. Y., et al. (2018). The role of the vaginal microbiome in gynaecological cancer. BJOG 125 , 309-315. doi: 10.1111/1471-0528.14631

Chase, D., Goulder, A., Zenhausern, F., Monk, B., and Herbst-Kralovetz, M. (2015). The vaginal and gastrointestinal microbiomes in gynecologic cancers: a review of applications in etiology, symptoms and treatment. Gynecol. Oncol. 138, 190-200. doi: 10.1016/j.ygyno.2015.04.036
Choi, S. C., Titov, A. A., Abboud, G., Seay, H. R., Brusko, T. M., Roopenian, D. C., et al. (2018). Inhibition of glucose metabolism selectively targets autoreactive follicular helper T cells. Nat. Commun. 9:4369. doi: 10.1038/s41467-01806686-0

Cong, J., Wang, X., Zheng, X., Wang, D., Fu, B., Sun, R., et al. (2018). Dysfunction of natural killer cells by FBP1-induced inhibition of glycolysis during lung cancer progression. Cell Metab. 28, 243.e5-255.e5. doi: 10.1016/j.cmet.2018.06. 021

Curty, G., Costa, R. L., Siqueira, J. D., Meyrelles, A. I., Machado, E. S., Soares, E. A., et al. (2017). Analysis of the cervical microbiome and potential biomarkers from postpartum HIV-positive women displaying cervical intraepithelial lesions. Sci. Rep. 7:17364. doi: 10.1038/s41598-017-17351-9

Curty, G., de Carvalho, P. S., and Soares, M. A. (2019). The role of the cervicovaginal microbiome on the genesis and as a biomarker of premalignant cervical intraepithelial neoplasia and invasive cervical cancer. Int. J. Mol. Sci. 21:222. doi: 10.3390/ijms21010222

Dallal, M. M. S., Yazdi, M. H., Holakuyee, M., Hassan, Z. M., Abolhassani, M., and Mahdavi, M. (2012). Lactobacillus casei ssp. casei induced Th1 cytokine profile and natural killer cells activity in invasive ductal carcinoma bearing mice. Iranian J. Allergy Asthma Immunol. 11, 183-189.

Di Paola, M., Sani, C., Clemente, A. M., Iossa, A., Perissi, E., Castronovo, G., et al. (2017). Characterization of cervico-vaginal microbiota in women developing persistent high-risk Human Papillomavirus infection. Sci. Rep. 7:10200. doi: 10.1038/s41598-017-09842-6

Doerflinger, S. Y., Throop, A. L., and Herbst-Kralovetz, M. M. (2014). Bacteria in the vaginal microbiome alter the innate immune response and barrier properties of the human vaginal epithelia in a species-specific manner. J. Infect. Dis. 209, 1989-1999. doi: 10.1093/infdis/jiu004

Drago, F., Herzum, A., Ciccarese, G., Dezzana, M., Casazza, S., Pastorino, A., et al. (2016). Ureaplasma parvumas a possible enhancer agent of HPV-induced cervical intraepithelial neoplasia: preliminary results. J. Med. Virol. 88, 20232024. doi: $10.1002 / \mathrm{jmv} .24583$

Erika, S., Koumans, E. H., Markowitz, L. E., Maya, S., Sawyer, M. K., David, S., et al. (2005). Association of Chlamydia trachomatis with persistence of highrisk types of human Papillomavirus in a cohort of female adolescents. Am. J. Epidemiol. 162:668. doi: 10.1093/aje/kwi262

Escarcega-Tame, M. A., Lopez-Hurtado, M., Escobedo-Guerra, M. R., ReyesMaldonado, E., Castro-Escarpulli, G., and Guerra-Infante, F. M. (2020). Coinfection between genotypes of the human papillomavirus and Chlamydia trachomatis in Mexican women. Int. J. STD AIDS 31, 1255-1262. doi: 10.1177/ 0956462420947587

Ferlay, J., Colombet, M., Soerjomataram, I., Mathers, C., Parkin, D. M., Pineros, M., et al. (2019). Estimating the global cancer incidence and mortality in 2018: GLOBOCAN sources and methods. Int. J. Cancer 144, 1941-1953. doi: 10.1002/ ijc.31937

Fernandes, J. V., De Medeiros Fernandes, T. A., De Azevedo, J. C., Cobucci, R. N., De Carvalho, M. G., Andrade, V. S., et al. (2015). Link between chronic inflammation and human Papillomavirus-induced carcinogenesis (Review). Oncol. Lett. 9, 1015-1026. doi: 10.3892/ol.2015. 2884

Ferrero-Miliani, L., Nielsen, O. H., Andersen, P. S., and Girardin, S. E. (2007). Chronic inflammation: importance of NOD2 and NALP3 in interleukin-1beta generation. Clin. Exp. Immunol. 147, 227-235. doi: 10.1111/j.1365-2249.2006. 03261.x

Fettweis, J. M., Brooks, J. P., Serrano, M. G., Sheth, N. U., Girerd, P. H., Edwards, D. J., et al. (2014). Differences in vaginal microbiome in African American women versus women of European ancestry. Microbiology 160, 2272-2282. doi: 10.1099/mic.0.081034-0

Fiorucci, S., and Distrutti, E. (2015). Bile acid-activated receptors, intestinal microbiota, and the treatment of metabolic disorders. Trends Mol. Med. 21, 702-714. doi: 10.1016/j.molmed.2015.09.001

Fischer, N. (2002). Chlamydia trachomatis infection in cervical intraepithelial neoplasia and invasive carcinoma. Eur. J. Gynaecol. Oncol. 23:247.

Flores, R., Shi, J., Fuhrman, B., Xu, X., Veenstra, T. D., Gail, M. H., et al. (2012). Fecal microbial determinants of fecal and systemic estrogens and estrogen metabolites: a cross-sectional study. J. Transl. Med. 10, 1-11. doi: 10.1186/14795876-10-253 
Foster, K. R., Chluter, J. S., Oyte, K. Z. C., and Rakoff-Nahoum, S. (2017). The evolution of the host microbiome as an ecosystem on a leash. Nature 548:43. doi: $10.1038 /$ nature 23292

Gabay, C., and Kushner, I. (1999). Acute-phase proteins and other systemic responses to inflammation. N. Engl. J. Med. 340:1376. doi: 10.1056/ NEJM199904293401723

Gajer, P., Brotman, R. M., Bai, G., Sakamoto, J., Schütte, U. M., Zhong, X., et al. (2012). Temporal dynamics of the human vaginal microbiota. Sci. Transl. Med. 4:132ra52. doi: 10.1126/scitranslmed.3003605

Garcea, G., Dennison, A. R., Steward, W. P., and Berry, D. P. (2005). Role of inflammation in pancreatic carcinogenesis and the implications for future therapy. Pancreatology 5, 514-529. doi: 10.1159/000087493

Germolec, D. R., Shipkowski, K. A., Frawley, R. P., and Evans, E. (2018). Markers of Inflammation. Methods Mol. Biol. 1803, 57-79. doi: 10.1007/978-1-4939-85494 _5

Godoy-Vitorino, F., Romaguera, J., Zhao, C., Vargas-Robles, D., Ortiz-Morales, G., Vazquez-Sanchez, F., et al. (2018). Cervicovaginal fungi and bacteria associated with cervical intraepithelial neoplasia and high-risk human Papillomavirus infections in a hispanic population. Front. Microbiol. 9:2533. doi: 10.3389/ fmicb.2018.02533

Goedert, J. J., Jones, G., Hua, X., Xu, X., Yu, G., Flores, R., et al. (2015). Investigation of the association between the fecal microbiota and breast cancer in postmenopausal women: a population-based case-control pilot study. J. Natl. Cancer Inst. 107:djv147. doi: 10.1093/jnci/djv147

Gosmann, C., Anahtar, M. N., Handley, S. A., Farcasanu, M., Abu-Ali, G., Bowman, B. A., et al. (2017). Lactobacillus-deficient cervicovaginal bacterial communities are associated with increased HIV acquisition in young South African women. Immunity 46, 29-37. doi: 10.1016/j.immuni.2016.12.013

Grivennikov, S. I., Wang, K., Mucida, D., Stewart, C. A., and Karin, M. (2013). Adenoma-linked barrier defects and microbial products drive IL-23/IL-17mediated tumour growth. Nature 491, 254-258. doi: 10.1038/nature11465

Gupta, S., Kumar, P., and Das, B. C. (2018). HPV: molecular pathways and targets. Curr. Probl. Cancer 42, 161-174. doi: 10.1016/j.currproblcancer.2018.03.003

Hong, S., and Laimins, L. A. (2013). The JAK-STAT transcriptional regulator, STAT-5, activates the ATM DNA damage pathway to induce HPV 31 genome amplification upon epithelial differentiation. PLoS Pathog. 9:e1003295. doi: 10. 1371/journal.ppat.1003295

Ilhan, Z. E., Laniewski, P., Thomas, N., Roe, D. J., Chase, D. M., and Herbst-Kralovetz, M. M. (2019). Deciphering the complex interplay between microbiota, HPV, inflammation and cancer through cervicovaginal metabolic profiling. EBioMedicine 44, 675-690. doi: 10.1016/j.ebiom.2019.04.028

Jenmalm, M. C. (2017). The mother-offspring dyad: microbial transmission, immune interactions and allergy development. J. Intern. Med. 282, 484-495. doi: 10.1111 /joim. 12652

Jespers, V., Kyongo, J., Joseph, S., Hardy, L., Cools, P., Crucitti, T., et al. (2017). A longitudinal analysis of the vaginal microbiota and vaginal immune mediators in women from sub-Saharan Africa. Sci. Rep. 7:11974. doi: 10.1038/s41598-01712198-6

Johnson, D. E., O'Keefe, R. A., and Grandis, J. R. (2018). Targeting the IL6/JAK/STAT3 signalling axis in cancer. Nat. Rev. Clin. Oncol. 15, 234-248. doi: $10.1038 /$ nrclinonc. 2018.8

Jouhi, L., Renkonen, S., Atula, T., Makitie, A., Haglund, C., and Hagstrom, J. (2014). Different toll-like receptor expression patterns in progression toward cancer. Front. Immunol. 5:638. doi: 10.3389/fimmu.2014.00638

Kipanyula, M. J., Seke Etet, P. F., Vecchio, L., Farahna, M., Nukenine, E. N., and Nwabo Kamdje, A. H. (2013). Signaling pathways bridging microbial-triggered inflammation and cancer. Cell. Signal. 25, 403-416. doi: 10.1016/j.cellsig.2012. 10.014

Klein, C., Gonzalez, D., Samwel, K., Kahesa, C., Mwaiselage, J., Aluthge, N., et al. (2019). Relationship between the cervical microbiome, HIV status, and precancerous lesions. mBio 10:e02785-18. doi: 10.1128/mBio.02785-18

Klein, C., Kahesa, C., Mwaiselage, J., West, J. T., Wood, C., and Angeletti, P. C. (2020a). How the cervical microbiota contributes to cervical cancer risk in subSaharan Africa. Front. Cell Infect. Microbiol. 10:23. doi: 10.3389/fcimb.2020. 00023

Klein, C., Samwel, K., Kahesa, C., Mwaiselage, J., and Angeletti, P. C. (2020b). Mycoplasma co-infection is associated with cervical cancer risk. Cancers 12:1093. doi: $10.3390 /$ cancers 12051093
Kostic, A. D., Chun, E., Robertson, L., Glickman, J. N., Gallini, C. A., Michaud, M., et al. (2013). Fusobacterium nucleatum potentiates intestinal tumorigenesis and modulates the tumor-immune microenvironment. Cell Host Microbe 14, 207-215. doi: 10.1016/j.chom.2013.07.007

Kovachev, S. M. (2020). Cervical cancer and vaginal microbiota changes. Arch. Microbiol. 202, 323-327. doi: 10.1007/s00203-019-01747-4

Kyrgiou, M., Mitra, A., and Moscicki, A. B. (2017). Does the vaginal microbiota play a role in the development of cervical cancer? Transl. Res. 179, 168-182. doi: 10.1016/j.trsl.2016.07.004

Laniewski, P., Barnes, D., Goulder, A., Cui, H., Roe, D. J., Chase, D. M., et al. (2018). Linking cervicovaginal immune signatures, HPV and microbiota composition in cervical carcinogenesis in non-Hispanic and Hispanic women. Sci. Rep. 8:7593. doi: 10.1038/s41598-018-25879-7

Laniewski, P., Ilhan, Z. E., and Herbst-Kralovetz, M. M. (2020). The microbiome and gynaecological cancer development, prevention and therapy. Nat. Rev. Urol. 17, 232-250. doi: 10.1038/s41585-020-0286-z

Li, Y., Yu, T., Yan, H., Li, D., Yu, T., Yuan, T., et al. (2020). Vaginal microbiota and HPV infection: novel mechanistic insights and therapeutic strategies. Infect. Drug Resist. 13, 1213-1220. doi: 10.2147/idr.S210615

Liang, Y., Chen, M., Qin, L., Wan, B., and Wang, H. (2019). A meta-analysis of the relationship between vaginal microecology, human Papillomavirus infection and cervical intraepithelial neoplasia. Infect. Agent Cancer 14:29. doi: 10.1186/ s13027-019-0243-8

Liu, C., Li, J., Shi, W., Zhang, L., Liu, S., Lian, Y., et al. (2020). Progranulin regulates inflammation and tumor. Antiinflamm. Antiallergy Agents Med. Chem. 19, 88-102. doi: 10.2174/1871523018666190724124214

Lv, P., Zhao, F., Xu, X., Xu, J., and Zhao, Z. (2019). Correlation between common lower genital tract microbes and high-risk human Papillomavirus infection. Can. J. Infect. Dis. Med. Microbiol. 2019:9678104. doi: 10.1155/2019/ 9678104

MacIntyre, D. A., Chandiramani, M., Lee, Y. S., Kindinger, L., Smith, A., Angelopoulos, N., et al. (2015). The vaginal microbiome during pregnancy and the postpartum period in a European population. Sci. Rep. 5:8988. doi: 10.1038/srep08988

Maldonado-Barragan, A., Caballero-Guerrero, B., Martin, V., Ruiz-Barba, J. L., and Rodriguez, J. M. (2016). Purification and genetic characterization of gassericin E, a novel co-culture inducible bacteriocin from Lactobacillus gasseri EV1461 isolated from the vagina of a healthy woman. BMC Microbiol. 16:37. doi: 10 . 1186/s12866-016-0663-1

Mhatre, M., McAndrew, T., Carpenter, C., Burk, R. D., Einstein, M. H., and Herold, B. C. (2012). Cervical intraepithelial neoplasia is associated with genital tract mucosal inflammation. Sex Transm. Dis. 39, 591-597. doi: 10.1097/OLQ. 0b013e318255aeef

Miller, K. D., Goding Sauer, A., Ortiz, A. P., Fedewa, S. A., Pinheiro, P. S., Tortolero-Luna, G., et al. (2018). Cancer statistics for hispanics/latinos, 2018. CA Cancer J. Clin. 68, 425-445. doi: 10.3322/caac.21494

Mima, K., Nishihara, R., Qian, Z. R., Cao, Y., Sukawa, Y., Nowak, J. A., et al. (2016). Fusobacterium nucleatum in colorectal carcinoma tissue and patient prognosis. Gut 65, 1973-1980. doi: 10.1136/gutjnl-2015-310101

Mirmonsef, P., Hotton, A. L., Gilbert, D., Gioia, C. J., Maric, D., Hope, T. J., et al. (2016). Glycogen levels in undiluted genital fluid and their relationship to vaginal pH, estrogen, and progesterone. PLoS One 11:e0153553. doi: 10.1371/ journal.pone.0153553

Mitra, A., MacIntyre, D. A., Lee, Y. S., Smith, A., Marchesi, J. R., Lehne, B., et al. (2015). Cervical intraepithelial neoplasia disease progression is associated with increased vaginal microbiome diversity. Sci. Rep. 5:16865. doi: 10.1038/ srep 16865

Mitra, A., MacIntyre, D. A., Marchesi, J. R., Lee, Y. S., Bennett, P. R., and Kyrgiou, M. (2016). The vaginal microbiota, human Papillomavirus infection and cervical intraepithelial neoplasia: what do we know and where are we going next? Microbiome 4:58. doi: 10.1186/s40168-016-0203-0

Motevaseli, E., Shirzad, M., Akrami, S. M., Mousavi, A. S., Mirsalehian, A., and Modarressi, M. H. (2013a). Normal and tumour cervical cells respond differently to vaginal lactobacilli, independent of $\mathrm{pH}$ and lactate. J. Med. Microbiol. 62, 1065-1072. doi: 10.1099/jmm.0.057521-0

Motevaseli, E., Shirzad, M., Raoofian, R., Hasheminasab, S. M., Hatami, M., Dianatpour, M., et al. (2013b). Differences in vaginal lactobacilli composition of Iranian healthy and bacterial vaginosis infected women: a comparative analysis 
of their cytotoxic effects with commercial vaginal probiotics. Iran. Red. Crescent. Med. J. 15, 199-206. doi: 10.5812/ircmj.3533

Muhleisen, A. L., and Herbst-Kralovetz, M. M. (2016). Menopause and the vaginal microbiome. Maturitas 91, 42-50. doi: 10.1016/j.maturitas.2016. 05.015

Muñoz, N., Bosch, F. X., Sanjosé, S. D., Herrero, R., Castellsagué, X., Shah, K. V., et al. (2003). Epidemiologic classification of human Papillomavirus types associated with cervical cancer. N. Engl. J. Med. 348, 518-527. doi: 10.1056/ NEJMoa021641

Nasioudis, D., Beghini, J., Bongiovanni, A. M., Giraldo, P. C., Linhares, I. M., and Witkin, S. S. (2015). alpha-amylase in vaginal fluid: association with conditions favorable to dominance of Lactobacillus. Reprod. Sci. 22, 1393-1398. doi: 10. $1177 / 1933719115581000$

Nelson, T. M., Borgogna, J. L., Brotman, R. M., Ravel, J., Walk, S. T., and Yeoman, C. J. (2015). Vaginal biogenic amines: biomarkers of bacterial vaginosis or precursors to vaginal dysbiosis? Front. Physiol. 6:253. doi: 10.3389/fphys.2015. 00253

Norenhag, J., Du, J., Olovsson, M., Verstraelen, H., Engstrand, L., and Brusselaers, N. (2020). The vaginal microbiota, human Papillomavirus and cervical dysplasia: a systematic review and network meta-analysis. BJOG 127, 171-180. doi: 10.1111/1471-0528.15854

Nunn, K. L., and Forney, L. J. (2016). Unraveling the dynamics of the human vaginal microbiome. Yale J. Biol. Med. 89, 331-337.

Oh, H. Y., Kim, B. S., Seo, S. S., Kong, J. S., Lee, J. K., Park, S. Y., et al. (2015). The association of uterine cervical microbiota with an increased risk for cervical intraepithelial neoplasia in Korea. Clin. Microbiol. Infect. 21, e671-e679. doi: 10.1016/j.cmi.2015.02.026

Olusola, P., Banerjee, H. N., Philley, J. V., and Dasgupta, S. (2019). Human papilloma virus-associated cervical cancer and health disparities. Cells 8:622. doi: $10.3390 /$ cells 8060622

Paavonen, J. (2012). Chlamydia trachomatis infections of the female genital tract: state of the art. Ann. Med. 44, 18-28. doi: 10.3109/07853890.2010.54 6365

Pakish, J. B., and Jazaeri, A. A. (2017). Immunotherapy in gynecologic cancers: are we there yet? Curr. Treat. Options Oncol. 18:59. doi: 10.1007/s11864-017$0504-y$

Pique, N., Berlanga, M., and Minana-Galbis, D. (2019). Health benefits of heatkilled (Tyndallized) probiotics: an overview. Int. J. Mol. Sci. 20:2534. doi: 10. 3390/ijms20102534

Plottel, C., and Blaser, M. (2011). Microbiome and malignancy. Cell Host Microbe 10, 324-335. doi: 10.1016/j.chom.2011.10.003

Rajagopala, S. V., Vashee, S., Oldfield, L. M., Suzuki, Y., Venter, J. C., Telenti, A., et al. (2017). The human microbiome and cancer. Cancer Prevent. Res. 10, 226-234. doi: 10.1158/1940-6207.CAPR-16-0249

Reed, N., Balega, J., Barwick, T., Buckley, L., Burton, K., Eminowicz, G., et al. (2021). British Gynaecological Cancer Society (BGCS) cervical cancer guidelines: recommendations for practice. Eur. J. Obstet. Gynecol. Reprod. Biol. 256, 433-465. doi: 10.1016/j.ejogrb.2020.08.020

Ridlon, J. M., Harris, S. C., Bhowmik, S., Kang, D. J., and Hylemon, P. B. (2016). Consequences of bile salt biotransformations by intestinal bacteria. Gut Microbes 7, 22-39. doi: 10.1080/19490976.2015.1127483

Riley, J. L. (2009). PD-1 signaling in primary T cells. Immunol. Rev. 229, 114-125. doi: $10.1111 /$ j.1600-065X.2009.00767.x

Romero, R., Hassan, S. S., Gajer, P., Tarca, A. L., and Ravel, J. (2014). The composition and stability of the vaginal microbiota of normal pregnant women is different from that of non-pregnant women. Microbiome 2, 4-4. doi: 10.1186/ 2049-2618-2-4

Round, J. L., and Mazmanian, S. K. (2009). The gut microbiota shapes intestinal immune responses during health and disease. Nat. Rev. Immunol. 9, 313-323. doi: $10.1038 /$ nri2515

Routy, B., Le Chatelier, E., Derosa, L., Duong, C. P., Alou, M. T., Daillère, R., et al. (2018). Gut microbiome influences efficacy of PD-1-based immunotherapy against epithelial tumors. Science 359, 91-97. doi: 10.1126/science.aan3706

Schäfer, G., Kabanda, S., Van Rooyen, B., Marušič, M. B., Banks, L., and Parker, M. I. (2013). The role of inflammation in HPV infection of the Oesophagus. BMC Cancer 13:185. doi: 10.1186/1471-2407-13-185

Schwabe, R. F., and Jobin, C. (2013). The microbiome and cancer. Nat. Rev. Cancer 13, 800-812. doi: $10.1038 / \mathrm{nrc} 3610$
Seo, S. S., Oh, H. Y., Lee, J. K., Kong, J. S., Lee, D. O., and Kim, M. K. (2016). Combined effect of diet and cervical microbiome on the risk of cervical intraepithelial neoplasia. Clin. Nutr. 35, 1434-1441. doi: 10.1016/j.clnu.2016.03. 019

Shin, R., Itoh, Y., Kataoka, M., Ino-Miura, S., Miura, R., Mizutani, T., et al. (2016). Anti-tumor activity of heat-killed Lactobacillus plantarum BF-LP284 on Meth-A tumor cells in BALB/c mice. Int. J. Food Sci. Nutr. 67, 641-649. doi: 10.1080/09637486.2016.1185771

Shmuely, H., Melzer, E., Braverman, M., Domniz, N., and Yahav, J. (2014). Helicobacter pylori infection is associated with advanced colorectal neoplasia. Scand. J. Gastroenterol. 49, 35-42. doi: 10.3109/00365521.2013.848468

Shukla, S., Jadli, M., Thakur, K., Shishodia, G., Mahata, S., Basir, S. F., et al. (2019). Level of phospho-STAT3 (Tyr705) correlates with copy number and physical state of human Papillomavirus 16 genome in cervical precancer and cancer lesions. PLoS One 14:e0222089. doi: 10.1371/journal.pone.0222089

Silva, J., Cerqueira, F. T., and Medeiros, R. (2014). Chlamydia trachomatis infection: implications for HPV status and cervical cancer. Arch. Gynecol. Obstetr. 289, 715-723. doi: 10.1007/s00404-013-3122-3

So, K. A., Yang, E. J., Kim, N. R., Hong, S. R., Lee, J. H., Hwang, C. S., et al. (2020). Changes of vaginal microbiota during cervical carcinogenesis in women with human Papillomavirus infection. PLoS One 15:e0238705. doi: 10.1371/journal. pone. 0238705

Sodhani, P., Gupta, S., Gupta, R., and Mehrotra, R. (2017). Bacterial vaginosis and cervical intraepithelial neoplasia: is there an association or is co-existence incidental? Asian Pac. J. Cancer Prev. 18, 1289-1292. doi: 10.22034/APJCP. 2017.18.5.1289

Sommer, F., Anderson, J. M., Bharti, R., Raes, J., and Rosenstiel, P. (2017). The resilience of the intestinal microbiota influences health and disease. Nat. Rev. Microbiol. 15, 630-638. doi: 10.1038/nrmicro.2017.58

Spear, G. T., French, A. L., Gilbert, D., Zariffard, M. R., Mirmonsef, P., Sullivan, T. H., et al. (2014). Human alpha-amylase present in lower-genitaltract mucosal fluid processes glycogen to support vaginal colonization by Lactobacillus. J. Infect. Dis. 210, 1019-1028. doi: 10.1093/infdis/jiu231

Srinivasan, S., Morgan, M. T., Fiedler, T. L., Djukovic, D., Hoffman, N. G., Raftery, D., et al. (2015). Metabolic signatures of bacterial vaginosis. mBio 6:e00204-15. doi: $10.1128 / \mathrm{mBio} .00204-15$

Stanley, M. A. (2012). Epithelial cell responses to infection with human Papillomavirus. Clin. Microbiol. Rev. 25, 215-222. doi: 10.1128/CMR.05028-11

Stelzle, D., Tanaka, L. F., Lee, K. K., Ibrahim Khalil, A., Baussano, I., Shah, A. S. V., et al. (2021). Estimates of the global burden of cervical cancer associated with HIV. Lancet Glob. Health 9, e161-e169. doi: 10.1016/s2214-109x(20)30459-9

Subramaniam, Y., Subban, K., and Chelliah, J. (2021). A novel synergistic anticancer effect of fungal cholestanol glucoside and paclitaxel: apoptosis induced by an intrinsic pathway through ROS generation in cervical cancer cell line (HeLa). Toxicol. In Vitro 72:105079. doi: 10.1016/j.tiv.2021.105079

Sun, S., Li, H., Chen, J., and Qian, Q. (2017). Lactic acid: no longer an inert and end-product of glycolysis. Physiology 32, 453-463. doi: 10.1152/physiol.00016. 2017

Swidsinski, A., Loening-Baucke, V., Mendling, W., Dörffel, Y., Schilling, J., Halwani, Z., et al. (2014). Infection through structured polymicrobial Gardnerella biofilms (StPM-GB). Histol. Histopathol. 29, 567-587. doi: 10.1016/ j.celrep.2014.02.040

Tanoue, T., Morita, S., Plichta, D. R., Skelly, A. N., Suda, W., Sugiura, Y., et al. (2019). A defined commensal consortium elicits CD8 T cells and anti-cancer immunity. Nature 565, 600-605. doi: 10.1038/s41586-019-0878-z

Tatsugami, M., Ito, M., Tanaka, S., Yoshihara, M., Matsui, H., Haruma, K., et al. (2012). Bile acid promotes intestinal metaplasia and gastric carcinogenesis. Cancer Epidemiol. Biomark. Prevent. 21, 2101-2107. doi: 10.1158/1055-9965. Epi-12-0730

Taylorrobinson, D., and Jensen, J. S. (2011). Mycoplasma genitalium: from chrysalis to multicolored butterfly. Clin. Microbiol. Rev. 24, 498-514. doi: 10.1128/CMR. 00006-11

Torcia, M. G. (2019). Interplay among vaginal microbiome, immune response and sexually transmitted viral infections. Int. J. Mol. Sci. 20:266. doi: 10.3390/ ijms20020266

Torres-Poveda, K., Burguete-Garcia, A. I., Bahena-Roman, M., Mendez-Martinez, R., Zurita-Diaz, M. A., Lopez-Estrada, G., et al. (2016). Risk allelic load in Th2 and Th3 cytokines genes as biomarker of susceptibility to HPV-16 positive 
cervical cancer: a case control study. BMC Cancer 16:330. doi: 10.1186/s12885016-2364- 4

Tsay, J. J., Wu, B. G., Badri, M. H., Clemente, J. C., Shen, N., Peter, M., et al. (2018). Airway microbiota is associated with up-regulation of the PI3K pathway in lung cancer. Am. J. Respir. Crit. Care Med. 198, 1188-1198. doi: 10.1164/rccm. 201710-2118OC

Urbaniak, C., Gloor, G. B., Brackstone, M., Scott, L., and Reid, G. (2016). The microbiota of breast tissue and its association with breast cancer. Appl. Environ. Microbiol. 82, 5039-5048. doi: 10.1128/AEM.01235-16

Valenti, P., Rosa, L., Capobianco, D., Lepanto, M. S., Schiavi, E., Cutone, A., et al. (2018). Role of Lactobacilli and Lactoferrin in the mucosal cervicovaginal defense. Front. Immunol. 9:376. doi: 10.3389/fimmu.2018.00376

Van de Wiele, T., Van Praet, J. T., Marzorati, M., Drennan, M. B., and Elewaut, D. (2016). How the microbiota shapes rheumatic diseases. Nat. Rev. Rheumatol. 12, 398-411. doi: 10.1038/nrrheum.2016.85

van de Wijgert, J. H., Borgdorff, H., Verhelst, R., Crucitti, T., Francis, S., Verstraelen, H., et al. (2014). The vaginal microbiota: what have we learned after a decade of molecular characterization? PLoS One 9:e105998. doi: 10.1371/ journal.pone.0105998

van der Meulen, T. A., Harmsen, H., Bootsma, H., Spijkervet, F., Kroese, F., and Vissink, A. (2016). The microbiome-systemic diseases connection. Oral Dis. 22, 719-734. doi: 10.1111/odi.12472

Verhoeven, V., Renard, N., Makar, A., Van Royen, P., Bogers, J. P., Lardon, F., et al. (2013). Probiotics enhance the clearance of human Papillomavirus-related cervical lesions: a prospective controlled pilot study. Eur. J. Cancer Prev. 22, 46-51. doi: 10.1097/CEJ.0b013e328355ed23

Verteramo, R., Pierangeli, A., Mancini, E., Calzolari, E., and Degener, A. M. (2009). Human Papillomaviruses and genital co-infections in gynaecological outpatients. BMC Infect. Dis. 9:16. doi: 10.1186/1471-2334-9-16

Vétizou, M., Pitt, J. M., Daillère, R., Lepage, P., Waldschmitt, N., Flament, C., et al. (2015). Anticancer immunotherapy by CTLA-4 blockade relies on the gut microbiota. Science 350, 1079-1084. doi: 10.1126/science.aad1329

Viaud, S., Saccheri, F., Mignot, G., Yamazaki, T., Daillère, R., Hannani, D., et al. (2013). The intestinal microbiota modulates the anticancer immune effects of cyclophosphamide. Science 342, 971-976. doi: 10.1126/science. 1240537

Vielot, N., Hudgens, M. G., Mugo, N., Chitwa, M., Kimani, J., and Smith, J. (2015). The Role of Chlamydia trachomatis in high-risk human Papillomavirus persistence among female sex workers in Nairobi, Kenya. Sex Transm. Dis. 42, 305-311. doi: 10.1097/OLQ.0000000000000287

Vrabel, D., Pour, L., and Sevcikova, S. (2019). The impact of NF-kappaB signaling on pathogenesis and current treatment strategies in multiple myeloma. Blood Rev. 34, 56-66. doi: 10.1016/j.blre.2018.11.003

Wang, Y., Yu, Y.-H., Shen, K., Xiao, L., Luan, F., Mi, X.-J., et al. (2014). Cervical cancer screening and analysis of potential risk factors in 43,567 women in Zhongshan, China. Asian Pac. J. Cancer Prev. 15, 671-676. doi: 10.7314/APJCP. 2014.15.2.671

Wang, Z., Wang, Q., Zhao, J., Gong, L., Zhang, Y., Wang, X., et al. (2019). Altered diversity and composition of the gut microbiome in patients with cervical cancer. AMB Express 9:40. doi: 10.1186/s13568-019-0763-z

Wiik, J., Sengpiel, V., Kyrgiou, M., Nilsson, S., Mitra, A., Tanbo, T., et al. (2019). Cervical microbiota in women with cervical intra-epithelial neoplasia, prior to and after local excisional treatment, a Norwegian cohort study. BMC Womens Health 19:30. doi: 10.1186/s12905-019-0727-0
Witkin, S. S., Mendes-Soares, H., Linhares, I. M., Jayaram, A., Ledger, W. J., and Forney, L. J. (2013). Influence of vaginal bacteria and D- and L-lactic acid isomers on vaginal extracellular matrix metalloproteinase inducer: implications for protection against upper genital tract infections. mBio 4:e00460-13. doi: 10.1128/mBio.00460-13

Witkowska, M., and Smolewski, P. (2013). Helicobacter pylori infection, chronic inflammation, and genomic transformations in gastric MALT lymphoma. Mediators Inflamm. 2013:523170. doi: 10.1155/2013/523170

Yang, L., Wang, Y., Shi, S., Xie, L., Liu, T., Wang, Y., et al. (2018). The TNFalpha-induced expression of miR-130b protects cervical cancer cells from the cytotoxicity of TNF-alpha. FEBS Open Biol. 8, 614-627. doi: 10.1002/2211-5463. 12395

Yang, T. K., Chung, C. J., Chung, S. D., Muo, C. H., Chang, C. H., and Huang, C. Y. (2015). Risk of endometrial cancer in women with pelvic inflammatory disease: a nationwide population-based retrospective cohort Study. Medicine 94:e1278. doi: 10.1097/MD.0000000000001278

Ye, H., Song, T., Zeng, X., Li, L., Hou, M., and Xi, M. (2018). Association between genital mycoplasmas infection and human Papillomavirus infection, abnormal cervical cytopathology, and cervical cancer: a systematic review and metaanalysis. Arch. Gynecol. Obstetr. 297, 1377-1387. doi: 10.1007/s00404-0184733-5

Yu, H., Kortylewski, M., and Pardoll, D. (2007). Crosstalk between cancer and immune cells: role of STAT3 in the tumour microenvironment. Nat. Rev. Immunol. 7, 41-51. doi: 10.1038/nri1995

Yu, J., Feng, Q., Wong, S. H., Zhang, D., Liang, Q. Y., Qin, Y., et al. (2017). Metagenomic analysis of faecal microbiome as a tool towards targeted noninvasive biomarkers for colorectal cancer. Gut 66, 70-78. doi: 10.1136/gutjnl2015-309800

Zhang, S., Liu, F., Mao, X., Huang, J., Yang, J., Yin, X., et al. (2015). Elevation of miR-27b by HPV16 E7 inhibits PPARgamma expression and promotes proliferation and invasion in cervical carcinoma cells. Int. J. Oncol. 47, 17591766. doi: 10.3892/ijo.2015.3162

Zhou, X., Hansmann, M. A., Davis, C. C., Suzuki, H., Brown, C. J., Schutte, U., et al. (2010). The vaginal bacterial communities of Japanese women resemble those of women in other racial groups. FEMS Immunol. Med. Microbiol. 58, 169-181. doi: 10.1111/j.1574-695X.2009.00618.x

Conflict of Interest: The authors declare that the research was conducted in the absence of any commercial or financial relationships that could be construed as a potential conflict of interest.

Publisher's Note: All claims expressed in this article are solely those of the authors and do not necessarily represent those of their affiliated organizations, or those of the publisher, the editors and the reviewers. Any product that may be evaluated in this article, or claim that may be made by its manufacturer, is not guaranteed or endorsed by the publisher.

Copyright (c) 2021 Zhou, Long, Cheng, Luo, Wen and Gao. This is an open-access article distributed under the terms of the Creative Commons Attribution License (CC BY). The use, distribution or reproduction in other forums is permitted, provided the original author(s) and the copyright owner(s) are credited and that the original publication in this journal is cited, in accordance with accepted academic practice. No use, distribution or reproduction is permitted which does not comply with these terms. 